THERMOREVERSIBLE HYALURONAN-HYDROGEL AND

\title{
AUTOLOGOUS NUCLEUS PULPOSUS CELL DELIVERY REGENERATES HUMAN INTERVERTEBRAL DISCS IN AN EX VIVO, PHYSIOLOGICAL ORGAN CULTURE MODEL
}

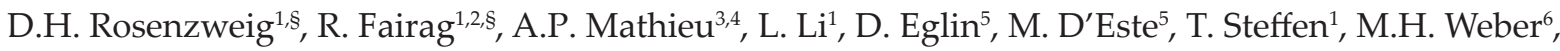 \\ J.A. Ouellet ${ }^{6}$ and L. Haglund ${ }^{1,6,7, *}$ \\ ${ }^{1}$ Orthopaedic Research Laboratory, Division of Orthopaedic Surgery, McGill University, \\ Montreal, Quebec, Canada \\ ${ }^{2}$ King Abdulaziz University, Jeddah, Saudi Arabia \\ ${ }^{3}$ Brain Imaging Centre, The Douglas Mental Health University Institute, McGill University, \\ Verdun, Quebec, Canada \\ ${ }^{4}$ Department of Psychiatry, McGill University, Montreal, Quebec, Canada \\ ${ }^{5} \mathrm{AO}$ Research Institute Davos, Davos, Switzerland \\ ${ }^{6}$ McGill Scoliosis and Spine Research Group, Montreal, Quebec, Canada \\ ${ }^{7}$ Shriners Hospital for Children, Montreal, Quebec, Canada \\ $\S$ These authors contributed equally
}

\begin{abstract}
Numerous studies show promise for cell-based tissue engineering strategies aiming to repair painful intervertebral disc (IVD) degeneration. However, clinical translation to human IVD repair is slow. In the present study, the regenerative potential of an autologous nucleus pulposus (NP)-cell-seeded thermoresponsive hyaluronic acid hydrogel in human lumbar IVDs was assessed under physiological conditions. First, agaroseencased in vitro constructs were developed, showing greater than $90 \%$ NP cell viability and high proteoglycan deposition within HA-pNIPAM hydrogels following 3 weeks of dynamic loading. Second, a bovine-induced IVD degeneration model was used to optimise and validate T1@ magnetic resonance imaging (MRI) for detection of changes in proteoglycan content in isolated intact IVDs. Finally, isolated intact human lumbar IVDs were pre-scanned using the established MRI sequence. Then, IVDs were injected with HA-pNIPAM hydrogel alone or autologous NP-cell-seeded. Next, the treated IVDs were cultured under cyclic dynamic loading for 5 weeks. Post-treatment T1@ values were significantly higher as compared to pre-treatment scans within the same IVD and region of interest. Histological evaluation of treated human IVDs showed that the implanted hydrogel alone accumulated proteoglycans, while those that contained NP cells also displayed neo-matrix-surrounded cells within the gel. The study indicated a clinical potential for repairing early degenerative human IVDs using autologous cells/hydrogel suspensions. This unique IVD culture setup, combined with the long-term physiological culture of intact human IVDs, allowed for a more clinically relevant evaluation of human tissue repair and regeneration, which otherwise could not be replicated using the available in vitro and in vivo models.
\end{abstract}

Keywords: Hydrogel, T1@ magnetic resonance imaging, human intervertebral disc, bioreactors, tissue engineering, nucleus pulposus, autologous cell implantation.

*Address for correspondence: Lisbet Haglund, McGill University, Department of Surgery, Montreal General Hospital, Room C10.148.2, 1650 Cedar Ave, Montreal, QC H3G 1A4, Canada.

Phone: $+15149341934 \quad$ Email: lisbet.haglund@mcgill.ca

Copyright policy: This article is distributed in accordance with Creative Commons Attribution Licence (http://creativecommons.org/licenses/by-sa/4.0/).

\section{Introduction}

Intervertebral discs (IVDs) are fibrocartilaginous tissues residing between the spinal vertebrae. They serve the main function of bearing and distributing mechanical load while also allowing flexion of the head, neck and trunk (Humzah and Soames, 1988). IVDs consist of the central, gelatinous nucleus 
pulposus (NP), which resists compressive load due to large amounts of hydrated proteoglycan (Nachemson, 1960), and the fibrous annulus fibrosus (AF), which surrounds the NP in concentric lamellar rings consisting mainly of aligned collagen type I fibrils, providing resistance to tensile strain (Marchand and Ahmed, 1990). The disc is flanked cranially and caudally by the cartilaginous endplates, which interface with the vertebral bone and allow for nutrient and waste diffusion into and out of the disc (Holm et al., 1981). The IVD extracellular matrix consists mainly of proteoglycans and collagens which directly contribute to disc mechanical function (McNally and Adams, 1992; Walter et al., 2011). $\mathrm{NP}$ and AF cells maintain the extracellular matrix through a balance of anabolic and catabolic turnover within the tissues (Sivan et al., 2006; Sivan et al., 2008). Due to their mostly avascular nature, IVDs cannot effectively self-repair upon injury (Alkhatib et al., 2014) and initiation of early degenerative events are closely associated with an imbalance in matrix homeostasis.

IVD degeneration is an age-related process that can be accelerated by numerous factors, including overload or trauma (Adams and Roughley, 2006; Roughley, 2004). Hallmarks of degeneration include decreased proteoglycan content, increased protease activity, increased inflammatory cytokines and neurotrophins, decreased water content, fragmentation in the extracellular matrix (ECM) components, decreased cellularity, increased fibrosis and loss of disc height (Adams and Roughley, 2006). All these factors ultimately contribute to loss of IVD mechanical function and directly contribute to chronic low back pain (Adams et al., 2014; Nachemson, 1975). Lower-back pain is a debilitating burden affecting millions of people around the world. Current treatment strategies are pain-management, physiotherapy or invasive surgical procedures, such as spine fusion or total disc replacement (Karppinen et al., 2011). Surgical procedures, such as fusion, may result in accelerated degeneration of adjacent levels (Tobert et al., 2017; Zhang et al., 2016). Therefore, there is a clinical need for identifying early disc degeneration and minimally invasive approaches for tissue repair prior to end-stage disc failure and necessity of invasive surgical intervention.

Use of cell-based therapies for early disc degeneration emerges as a potential treatment option for replenishing the cell population, proteoglycan content and ECM network within the central nucleus (Sakai and Andersson, 2015; Sakai and Grad, 2015). Slowing of degenerative processes and potential ECM replenishment may be achieved by autologous or allogeneic implantation of mesenchymal stem cells (MSCs) and NP cells. A few recent clinical trials show the potential benefits of implanting autologous and allogeneic MSCs (Noriega et al., 2017; Orozco et al., 2011; Yoshikawa et al., 2010) or NP cells (Mochida et al., 2015); yet, it is important to note that these cells are delivered without an injectable hydrogel material. A recent review describes the benefits of hydrogels as cells carriers for disc and soft tissue repair (Burdick et al., 2016). The premise is to harness various properties of hydrogels to protect, for example, MSCs from the harsh microenvironments of diseased or degenerate tissue where they are being implanted. The authors suggest that cells implanted within an injectable hydrogel may benefit, at least temporarily, from protection against biomechanical strains, low $\mathrm{pH}$, low glucose, low oxygen and high inflammatory conditions of the degenerating IVD (Burdick et al., 2016). Moreover, the hydrogel would fill any tissue fissures existing at the delivery site, providing hydration and support to the tissue and the implanted cells (Burdick et al., 2016). Poly(Nisopropylacrylamide) (pNIPAM)-based hydrogels are used in numerous studies for cartilage and IVD repair due to thermal and $\mathrm{pH}$ sensitivity toward gelation (de Vries-van Melle et al., 2014; Mortisen et al., 2010; Thorpe et al., 2016). One variation chemically links the major matrix carbohydrate polymer hyaluronic acid to pNIPAM (HA-pNIPAM) and shows promise in NP cell and MSC support (Peroglio et al., 2013; Peroglio et al., 2012). Its potential to support NP cell implantation into intact, isolated human IVDs is demonstrated (Rosenzweig et al., 2016b). However, the metabolic effects of dynamic loading on this cellseeded HA-pNIPAM hydrogel (and others) has yet to be determined.

IVD tissues are under constant dynamic mechanical load and this load is essential for the physiological metabolic processes of the disc cells (Bailey et al., 2017; Gawri et al., 2014a; MacLean et al., 2008; Paul et al., 2012). Therefore, it is imperative to consider mechanical loading when evaluating hydrogels as a means of cell delivery to IVD organ cultures for tissue repair. Bioreactors for long-term physiological organ culture of IVDs are developed to study the mechanisms of degeneration as well as repair and regeneration (Gantenbein et al., 2015). Such bioreactors can be modified to apply physiological dynamic load to agarose constructs that contain the HA-pNIPAM seeded with IVD cells. In this way, cell viability, differentiation and ECM production can be assessed and optimised prior to applying the cell-seeded hydrogels into intact IVDs (Gantenbein et al., 2015).

Following standard radiography techniques, the most widely used clinical method for noninvasively determining the IVD degenerative status is the magnetic resonance imaging (MRI) (Ract et al., 2015). T1-weighted images typically correspond to fat content while $\mathrm{T} 2$-weighted images relate to tissue water content. The Pfirrmann grading system (T2-weighted) is most commonly used to determine disc degeneration in patients suffering from back pain (Pfirrmann et al., 2001). An alternate T1Q-weighted MRI sequence is established to more accurately identify and quantify proteoglycanbound water, as pertinent to articular cartilage and intervertebral discs, whose matrices are proteoglycan- 
rich (Borthakur et al., 2006a; Borthakur et al., 2006b; Wang et al., 2007). Loss of proteoglycan content is a marker of early degenerative events and patients with early degeneration would be ideal candidates for cell-based therapies. T1@-weighted MRI is adapted to axially quantify proteoglycan content in cadaveric lumbar spine segments (Mulligan et al., 2014). Therefore, T10-weighted MRI can be used to directly quantify disc proteoglycan content and determine early IVD degeneration (Zobel et al., 2012). The present study aimed to further develop a human IVD organ culture model by testing the hypothesis that IVD repair and regeneration could be achieved by cell delivery within an injectable hydrogel carrier. The overall workflow is presented in Fig. 1. To assess and quantify whether this treatment repaired tissues, a non-invasive measure was required. Therefore, T1Q-weighted MRI was adapted for quantifying proteoglycan content in isolated intact human IVDs. Quantification of proteoglycan content prior to and after HA-pNIPAM alone or autologous NP-cell- seeded HA-pNIPAM delivery enabled full assessment of the potential of hydrogel and cell-based therapy in disc repair. That cell-seeded hydrogel delivery would fill tissue fissures, support cell delivery and improve T10-weighted MRI signal intensity and histological evaluation in early degenerate IVDs after 5 weeks of moderate dynamic loading in a custom bioreactor was further hypothesised.

\section{Materials and Methods}

\section{Human tissue and cell isolation}

Human IVDs and NP cells were isolated (Gawri et al., 2011; Rosenzweig et al., 2016a; Rosenzweig et al., 2017) from lumbar spine segments obtained after informed consent was given in collaboration with Transplant Quebec Organ Donation Program. Demographics are presented in Table 1. Briefly, spines were processed within $4 \mathrm{~h}$ post-mortem, soft tissue and ligaments were removed. X-ray radiographs were

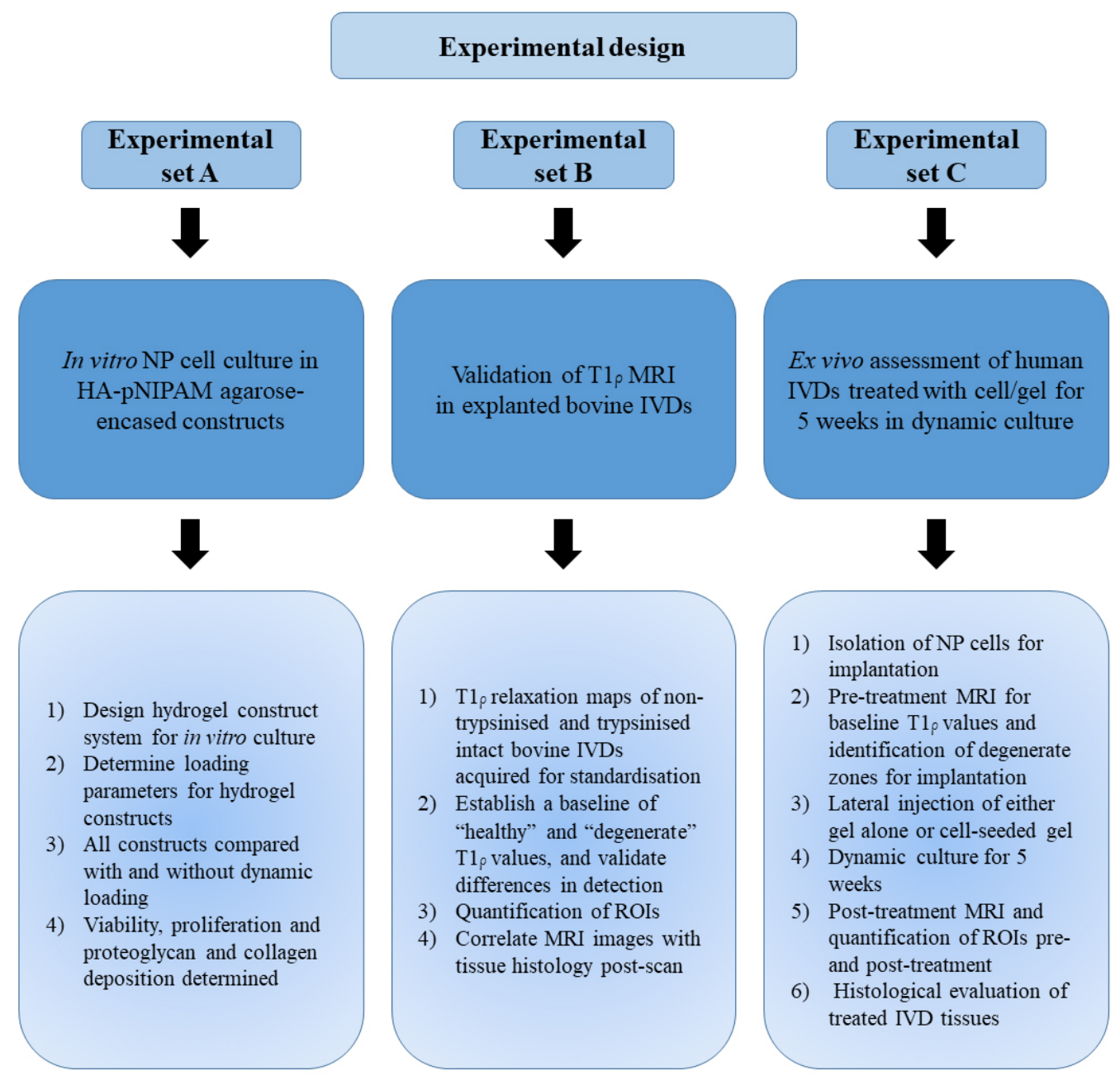

Fig. 1. Workflow of the experimental approach. Three different major experiments are presented in the present study. Experimental set A tested the effects of loading on isolated NP cells within the HA-pNIPAM constructs. Experimental set B determined the feasibility of using T1@ MRI to assess differences in matrix proteoglycan content using a bovine IVD-induced degeneration model. Experimental set C tested the effects of the hydrogel alone or autologous NP-cell-seeded hydrogels on human IVD regeneration after 5 weeks of dynamic physiological culture. 
Table 1. Specimen demographics indicating age, sex, cause of death (COD), level used, degeneration level, average disc height and for which purpose each disc was used.

\begin{tabular}{|c|c|c|c|c|c|c|c|c|}
\hline Donor & Age & Gender & COD & Disc level & Grade & $\begin{array}{c}\text { Average } \\
\text { height }(\mathrm{mm})\end{array}$ & $\begin{array}{c}\text { Disc diameter } \\
(\mathrm{mm})\end{array}$ & Usage \\
\hline \multirow{3}{*}{1} & \multirow{3}{*}{48} & \multirow{3}{*}{ Female } & \multirow{3}{*}{$\begin{array}{l}\text { Respiratory } \\
\text { arrest }\end{array}$} & L4-L5 & 3 & 9.8 & Not available & $\begin{array}{c}\text { Cell } \\
\text { isolation } \\
\end{array}$ \\
\hline & & & & T12-L1 & 3 & 9.0 & 44 & Gel alone \\
\hline & & & & L1-L2 & 3 & 9.2 & 49 & Gel + cells \\
\hline \multirow{3}{*}{2} & \multirow{3}{*}{46} & \multirow{3}{*}{ Male } & \multirow{3}{*}{ Anoxia } & L1-L2 & 3 & 8.1 & Not available & $\begin{array}{c}\text { Cell } \\
\text { isolation }\end{array}$ \\
\hline & & & & L3-L4 & 3 & 9.1 & 52 & Gel alone \\
\hline & & & & L4-L5 & 3 & 9.2 & 58 & Gel + cells \\
\hline \multirow{3}{*}{3} & \multirow{3}{*}{52} & \multirow{3}{*}{ Male } & \multirow{3}{*}{ Unknown } & T12-L1 & 3 & 8.4 & Not available & $\begin{array}{c}\text { Cell } \\
\text { isolation }\end{array}$ \\
\hline & & & & L1-L2 & 3 & 8.99 & 46 & Gel alone \\
\hline & & & & L2-L3 & 3 & 10.0 & 51 & Gel + cells \\
\hline
\end{tabular}

used to determine which segments showed the least signs of degeneration and the selected discs with grades 2-3 degeneration (Quint and Wilke, 2008) were isolated by parallel cuts close to the endplates, leaving approximately $3 \mathrm{~mm}$ of bone on each side of the disc. Final Thomson grading assessment (Alkhatib et al., 2014; Rosenzweig et al., 2016b) showed that all discs used were grade 3 degeneration (Table 1). Discs were further processed using a high-speed drill (Foredom, Bethel, CT, USA), fitted with a surgical fluted ball burr (Conmed Linvatec, Largo, FL, USA), to remove bone all the way until exposure of the softer, flexible cartilaginous endplate (Gawri et al., 2011). The discs were thoroughly rinsed three times in antibiotic solution, as previously described (Rosenzweig et al., 2016b), and placed in sterile polypropylene specimen containers ( $80 \mathrm{~mL}$ volume, STARPLEX Scientific, Etobicoke, ON, Canada) containing culture medium [Dulbecco's modified Eagle's medium (DMEM) supplemented with $1 \times$ Glutamax, $15 \mathrm{mM}$ 4-(2-hydroxyethyl)-1-piperazineethanesulphonic acid (HEPES), $5 \%$ foetal bovine serum, $50 \mu \mathrm{g} / \mathrm{mL}$ gentamycin, $50 \mu \mathrm{g} / \mathrm{mL}$ L-ascorbate] at a ratio of $3.5 \mathrm{~mL}$ of medium/g of tissue weight (Gawri et al., 2011). NP cells were isolated from adjacent levels of the same donor (Gawri et al., 2014b; Rosenzweig et al., 2016a; Rosenzweig et al., 2017) and expanded in culture for subsequent autologous injections. Cells were maintained in the first passage in culture for up to 1 week (DMEM high glucose with $15 \mathrm{mM}$ HEPES, $1 \times$ Glutamax, $10 \%$ foetal bovine serum and $1 \times$ gentamycin - all from Gibco) prior to injection into the corresponding autologous lumbar IVD following their MRI scans (see below).

\section{Human disc cell seeding in HA-pNIPAM,} viability and matrix deposition in dynamic load To assess whether isolated human NP cells remained viable and produce matrix within the HA-pNIPAM (Peroglio et al., 2012) under physiological conditions, an in vitro, dynamic compressive culture system simulating the disc physiological environment was designed (Fig. 2 and 3). The HA-pNIPAM used was designed to readily flow and fill smaller cavities in intact IVDs and did not have mechanical properties comparable to native IVD, with an elastic modulus of 1-2 kPa (Fig. 4). Therefore, an agarose and silicone tubing construct in which to embed the cellseeded HA-pNIPAM was designed, mimicking the mechanical competence of an IVD (Fig. 3a). The force needed to give $10 \%$ displacement was determined and the long-term stability of the constructs evaluated using an MTS Mini Bionix 858 mechanical testing machine (MTS Systems Corporation, Eden Prairie, MN, USA). Cyclic compression mechanical testing was performed on the silicone tubing with or without the agarose filling, to determine the force necessary to cause 10, 15 and $30 \%$ displacement (Fig. 3b, showing representative $15 \%$ displacement curve). Plungers were designed and produced by additive manufacturing to generate $200 \mu \mathrm{L}$ cavities within the agarose to fill with the cell-seeded HA-pNIPAM. After setting, the cell-seeded HA-pNIPAM was overlaid with molten agarose $\left(\sim 42^{\circ} \mathrm{C}\right)$ that rapidly cooled to $37^{\circ} \mathrm{C}$. The cell-seeded constructs were placed inside the bioreactor. The constructs were cultured under cyclic dynamic loading with $10 \%$ displacement for $21 \mathrm{~d}$. Load data were recovered and showed a consistent $10 \%$ displacement during cyclic loading periods (Fig. 3c). This was achieved without damaging the agarose casing or the HA-pNIPAM gel within.

The construct was made by pouring molten $2 \%$ tissue-culture-grade agarose (dissolved in sterile DMEM) (Sigma-Aldrich) into custom-cut $25 \mathrm{~mm}$ inner diameter silicone rings (standard tubing). To create a cavity within the construct, a custom plunger was designed in SketchUp software (Trimble Inc. Sunnyvale, CA, USA) and 3D-printed on a Flashforge Creator Pro (Flashforge Corporation, Zhejiang, China) (Fig. 3a), which left a cylindrical cavity with a maximum volume of $250 \mu \mathrm{L}$. Once filled with the gel/ 
cell suspension, $42^{\circ} \mathrm{C}$ molten agarose was overlaid. The bioreactor works by setting the force required for physiological displacement. To determine the force necessary for displacing the silicone rings/agarose constructs within a physiological range, the empty agarose constructs were cyclically loaded with 10 , 15 and $30 \%$ strain at $0.1 \mathrm{~Hz}$ without damaging the construct, using an MTS Mini Bionix 858 mechanical testing machine (MTS Systems Corporation) (Fig. 3). Cyclic compressive loading of $10 \%$ displacement at $0.1 \mathrm{~Hz}$ was chosen as the physiological range, as described by Gawri et al. (2014a) and Rosenzweig et al. (2016b). This force necessary for $10 \%$ displacement was applied in the bioreactor for in vitro experiments. $2 \times 10^{6} \mathrm{NP}$ cells/mL were encapsulated within the HA-pNIPAM injectable hydrogel and embedded within custom-made silicone/agarose constructs (Fig. 2 and 3). These constructs had the cavities filled with $200 \mu \mathrm{L}(\sim 500,000$ cells) of the gel/cell suspension and were cultured either without load or under dynamic compression (10\% of construct height) for 2 weeks in the bioreactor. A representative rheological analysis of one of the batches of HA-pNIPAM used in the study is shown in Fig. 4, matching previous reports (D'Este et al., 2012; D'Este et al., 2016). The load cycle was set to $2 \mathrm{~h}$ of dynamic load, $6 \mathrm{~h}$ of low static load, $2 \mathrm{~h}$ dynamic load and $14 \mathrm{~h}$ low static load, to represent a physiological sedentary lifestyle as previously described (Rosenzweig et al., 2016a). Cell viability was determined by LIVE/DEAD assay using fluorescent microscopy (Rosenzweig et al., 2016a).

\section{Bovine caudal disc isolation}

Bovine caudal intervertebral discs were extracted from tails of steers ranging from 18 to 21 months of age collected from a local abattoir (Les Viandes Forget, Terrebonne, QC, Canada) within $12 \mathrm{~h}$ of animal slaughter, as previously described (Gawri et al., 2014a; Haglund et al., 2011; Jim et al., 2011). Degeneration of bovine discs was induced by a single injection of $100 \mu \mathrm{g}$ of trypsin (Sigma-Aldrich) dissolved in $50 \mu \mathrm{L}$ phosphate-buffered saline (PBS) into the centre of the disc using a $28 \mathrm{G} 1 / 2$ needle (Gawri et al., 2014a). Injections were performed through the dorsal side of the disc. The needle was placed on top of the disc to measure the distance needed to reach the centre and was inserted to the same depth. Once in the centre, the trypsin solution was slowly injected and the needle gradually pulled out to avoid back flow. To reduce cell viability by $50 \%$, discs were simultaneously placed in glucose deprivation $(1 \mathrm{~g} / \mathrm{L})$ disc culture medium for $96 \mathrm{~h}$ and, then, back into standard glucose $(4.5 \mathrm{~g} / \mathrm{L})$ disc culture medium for recovery (Gawri et al., 2014a). This procedure was termed 'induced degeneration'.

\section{T10 MRI imaging and analysis}

All human and bovine discs were sutured on one side (to mark for MRI positioning) and cultured unloaded for 1 week. The discs were transferred to a sterile bag, filled with $20 \mathrm{~mL}$ of culture medium, air-bubbles-removed and sealed using a disinfected vacuum food-saver device. Then, the sealed discs were submersed vertically, with the suture side down, in sterilised tap water in a sterile, leak-proof container (Starplex Scientific, Etobicoke, ON, USA). These containers fit perfectly into a third-party $50 \mathrm{~mm}$ quadrature-driven volumetric transceiver awake rat imaging system (Animal Imaging Research, Holden, MA, USA). Healthy and degenerate bovine caudal discs (described above) were scanned to ensure that differences in T1@ values could be assessed for isolated discs, as previously determined for intact lumbar spines. Images were obtained on a 7T Bruker BioSpec 70/30 USR (Bruker Biospin, Milton, ON, Canada) with the high-performance mini-imaging

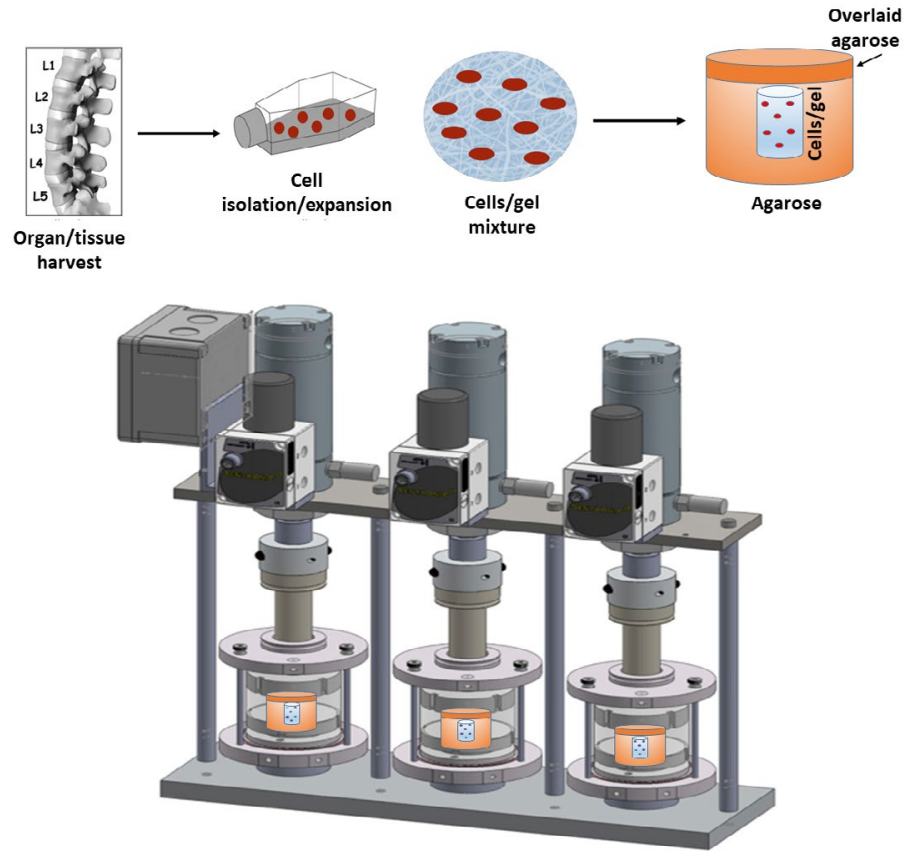

Fig. 2. Schematic representation of cell isolation, hydrogel embedding in agarose construct and bioreactor loading. Human lumbar discs and disc cells were isolated from lumbar spine. Cells isolated from adjacent segments (from IVDs to be used in implantation experiments) were expanded in monolayer culture. To test the effects of mechanical load on cells suspended in HA-pNIPAM, cell/gel suspensions were encased in agarose/ silicone moulds. Then, these were placed in the bioreactors for 3 weeks, after which viability, proliferation and matrix deposition could be assessed. 
a
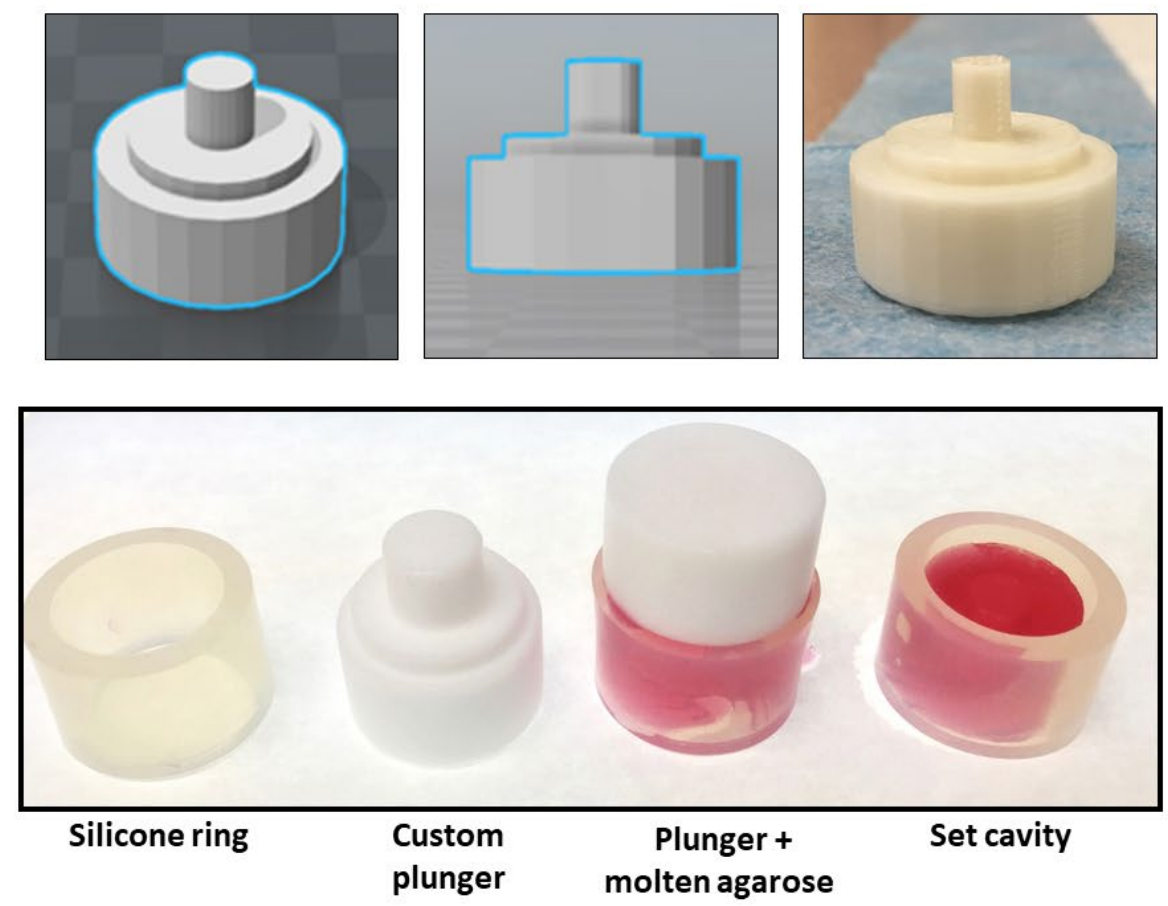

b
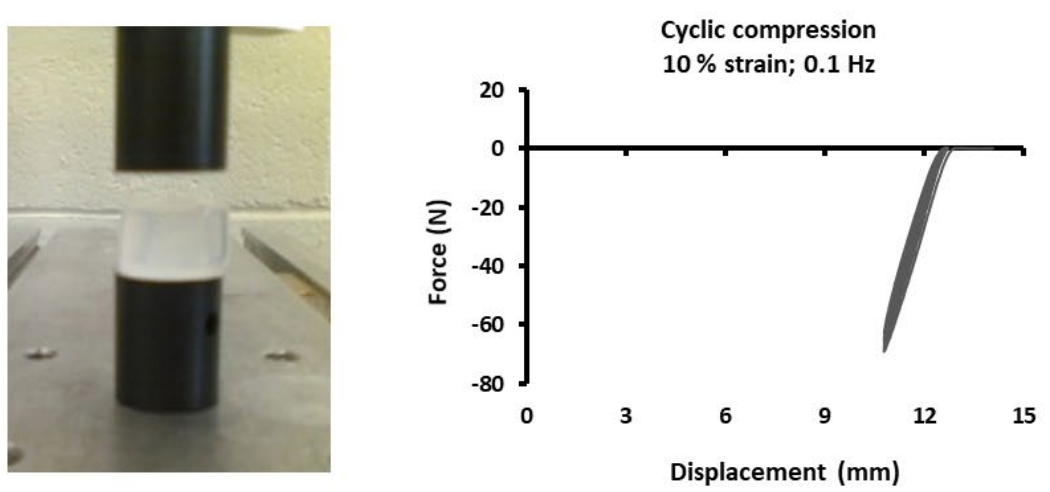

C

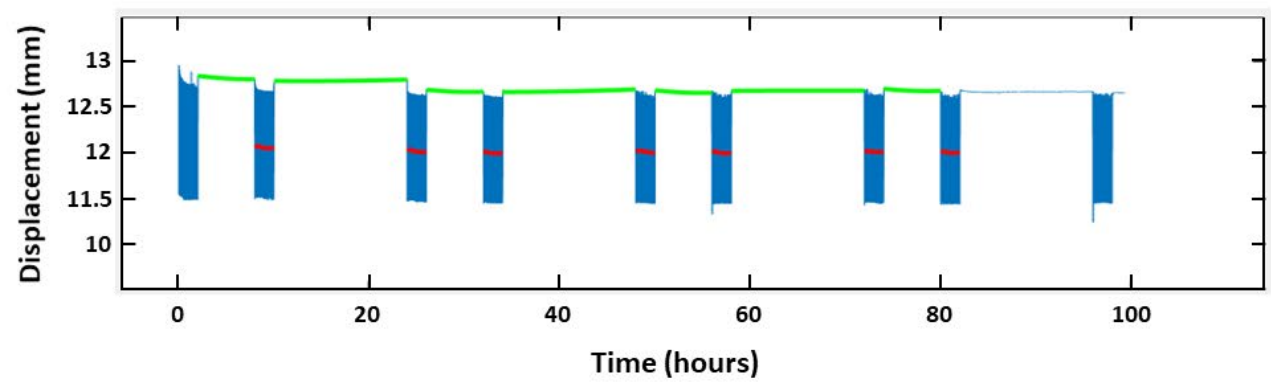

Fig. 3. Building of agarose moulds and determination of the force necessary for $10 \%$ compressive displacement. (a) Top line: representative computer-aided design drawings of custom plunger and an image of the 3D printed plunger used to cast cavities of desired volume in an agarose model. Bottom line: images showing silicone ring, plunger set in molten agarose and the formed cavity. Once the cell-seeded hydrogel is placed in the cavity, molten agarose is overlaid up to the full height of the silicone ring. (b) Representative image of construct on the MTS machine. The graph shows cyclic loading of $10 \%$ strain at $0.1 \mathrm{~Hz}$. The data show that a force of approximately $60 \mathrm{~N}$ is required in the bioreactor to generate dynamic load in the physiological range of $10 \%$ strain. (c) A representative $5 \mathrm{~d}$ load curve of a cell/gel construct on the bioreactor, showing consistent $~ 10 \%$ strain during the dynamic periods. 
kit gradient upgrade AVIII electronics (Bruker) and a Bruker-issued T1Q-RARE pulse sequence, as previously established (Mulligan et al., 2014), using the following parameters: echo time (TE) $20 \mathrm{~ms}$, repetition time (TR) $2500 \mathrm{~ms}$, flip angle $90^{\circ}$, field of view (FOV) $51.2 \times 51.2 \mathrm{~mm}$, matrix $342 \times 342$ points, in-plane resolution $0.15 \times 0.15 \mathrm{~mm}$, rapid acquisition with relaxation enhancement (RARE) factor 4 , receiver band width (BW) $69444.4 \mathrm{~Hz}$, number of excitations (NEX) 1 and time of acquisition (TA) $640 \mathrm{~s}$. Scans were performed with spin-lock durations of 10, 25, 50 and $100 \mathrm{~ms}$ at a fixed spinlocking strength of $11.7 \mu \mathrm{T}(500 \mathrm{~Hz})$ on a single slice of $1 \mathrm{~mm}$. Heat maps representing signal intensity were created using the MIPAV software (NIH Center for Information Technology, Bethesda, MD, USA). After MRI analysis, healthy and degenerate bovine discs were sagittally sectioned $(2 \mathrm{~mm})$ through the centre, fixed in periodate lysine paraformaldehyde (PLP) fixative and prepared for paraffin embedding. Then, all isolated human discs were scanned in sagittal and axial planes using the same imaging set-up as for the bovine discs, except for different 3D-FOV parameters and employing a single spin-lock duration of $10 \mathrm{~ms}$ for comparative analyses. Briefly, 3D images were acquired by obtaining sagittal plane slices consisting of 15 slices across the entire disc from left to right with $3 \mathrm{~mm}$ slice thickness (FOV $51.2 \times 51.2 \times 45 \mathrm{~mm}$, matrix $342 \times 324 \times 15$ points, resolution $0.15 \times 0.15 \times 3 \mathrm{~mm}$, TA $40 \mathrm{~min}$ ), while axial plane slices consisted of 8 slices per disc with thickness of $1.5 \mathrm{~mm}$ (FOV $51.2 \times 51.2 \times 12 \mathrm{~mm}$, matrix $342 \times 342 \times 8$ points, resolution $0.15 \times 0.15 \times 1.5 \mathrm{~mm}$, TA $1280 \mathrm{~s})$. T1 $\mathrm{Q}$ values were calculated and quantified for all the axial slices using the MIPAV software. T1@ values of 'before' and 'after' scans of each disc were normalised to the surrounding culture medium (strongest value) using editing features in MIPAV software. Specific regions of interest (ROIs) were drawn around regions indicating hydrogel of the

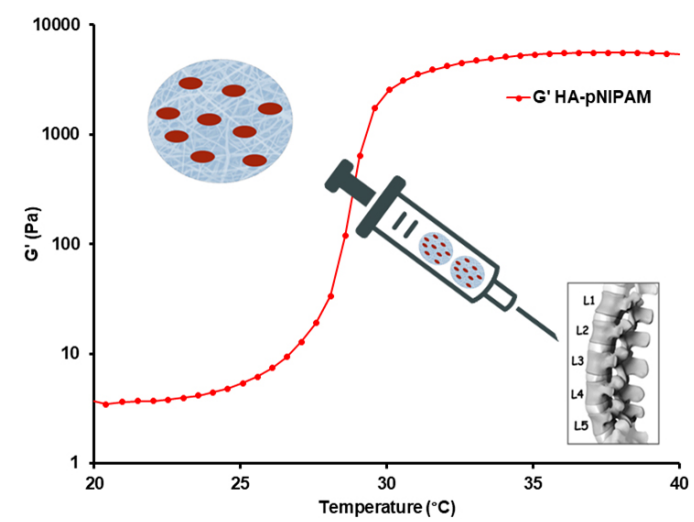

Fig. 4. Shear elastic modulus of HA-pNIPAM as a function of the temperature. The material was very soft at room temperature, allowing easy mixing with cells and their injection under lowshear. The elastic modulus increased over 3 orders of magnitude at body temperature, forming a gel with mechanical properties similar to the NP. 'after' images and superimposed onto the same region of the 'before' image. This was performed in the axial plane of slices 3-7 (out of 8) for each sample. The T1@ images were manually cropped by a single user (DHR) around the perimeter of the IVDs. The average of the $\mathrm{T} 1 \mathrm{Q}$ values was calculated within the ROIs for the hydrogel alone and the cell-seeded hydrogels from 3-7 slices (where gel could be clearly identified) per image in the axial plane.

Autologous cell implantation and bioreactor culture The bioreactor system design and culture approach for human lumbar IVDs is previously described (Rosenzweig et al., 2016a). The isolated, injected discs were cultured without external load for 7-10 d to gain booking access to the MRI and allow the growth of the isolated autologous NP cells to be implanted. Following pre-treatment MRI scanning, the corresponding cultured NP cells from the same donor were trypsinised in $2 \mathrm{~mL}$ of $0.25 \%$ trypsinethylenediaminetetraacetic acid (EDTA) (Invitrogen). The cells were washed in culture medium and counted using a haemocytometer. Next, they were suspended in HA-pNIPAM, as described (D'Este et al., 2012; Peroglio et al., 2013; Peroglio et al., 2012; Rosenzweig et al., 2016a), and approximately $1 \times 10^{6}$ cells were injected laterally into the disc using a $26 \mathrm{G}$ needle, with a total volume of $\sim 400 \mu \mathrm{L}$. Injected discs were placed under static load $(0.1 \mathrm{MPa})$ for $48 \mathrm{~h}$ and, then, dynamically loaded using a moderate loading protocol cycling in a sinusoidal pattern between 0.1 and $0.6 \mathrm{MPa}$ for two periods of $2 \mathrm{~h}$ each. The dynamic compressive load periods were interrupted by recovery periods of $6 \mathrm{~h}$ and $14 \mathrm{~h}$, respectively, maintaining a low-static $0.1 \mathrm{MPa}$ load (Rosenzweig et al., 2016b). The loading scheme was repeated for 35 consecutive days. Changes in disc height and axial load data were sampled continuously at $0.2 \mathrm{~Hz}$. After loading was completed, discs were packed in a sterile bag filled with $25 \mathrm{~mL}$ of culture medium, sealed and taken for post-treatment T1@ MRI scans. Discs used in the study were found to be corresponding to Thompson grade 2-3. This correlation was determined post-experimentation by macroscopic visualisation.

\section{Dimethylmethylene blue assay (DMMB)}

DMMB assays were performed as previously described (Alkhatib et al., 2014; Krock et al., 2017; Rosenzweig et al., 2016b), using the method by Mort and Roughley (Mort and Roughley, 2007) to quantify sulphated glycosaminoglycans (sGAGs). Chondroitin sulphate for standards were purchased from Sigma-Aldrich and $4 \mathrm{M} \mathrm{GuHCl}$ was added to standard curves when quantify tissue sGAG content.

Cell viability, histology, DNA and protein extraction After the $14 \mathrm{~d}$ of loaded and unloaded custom construct culture, cell-seeded hydrogel cores were harvested from the agarose enclosure. One set 
of samples was dedicated to LIVE/DEAD assay (Invitrogen), whereby $4 \mathrm{~mm}$ biopsy punches (Acuderm Inc., Ft. Lauderdale, FL, USA) were removed and submerged into the LIVE/DEAD solution, according to the manufacturer instructions. Live and dead cells were visualised and images captured using an inverted confocal laser scanning microscope (Zeiss LSM 510). Images were captured, merged and quantified, as described by Rosenzweig et al. (2016a). The other experimental replicates were dedicated for either PLP-fixation, cryo-embedding in Tissue-Tek ${ }^{\circledR}$ O.C.T. compound (VWR) or prepared for paraffin embedding. Protein and DNA were extracted on a weight/volume basis in 15 volumes extraction buffer [ $4 \mathrm{M} \mathrm{GuHCl}, 50 \mathrm{mM}$ sodium acetate $\mathrm{pH}$ 5.8, $10 \mathrm{mM}$ EDTA and $1 \times$ COMPLETE $^{\circledR}$ protease inhibitors (Roche)]. Tissue samples were incubated for $48 \mathrm{~h}$ at $4{ }^{\circ} \mathrm{C}$ under continuous agitation. Then, the extracts were cleared by centrifugation at $16,000 \times g$ for $30 \mathrm{~min}$.

\section{DNA Hoechst 33258 assay}

All GuHCl extracts were diluted 10-fold to fall within a previously reported range acceptable for Hoechst assay (Hoemann, 2004). To adjust for any interference a

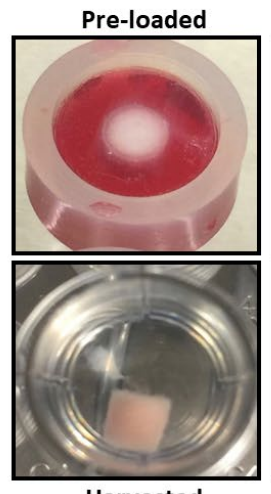

Harvested

b
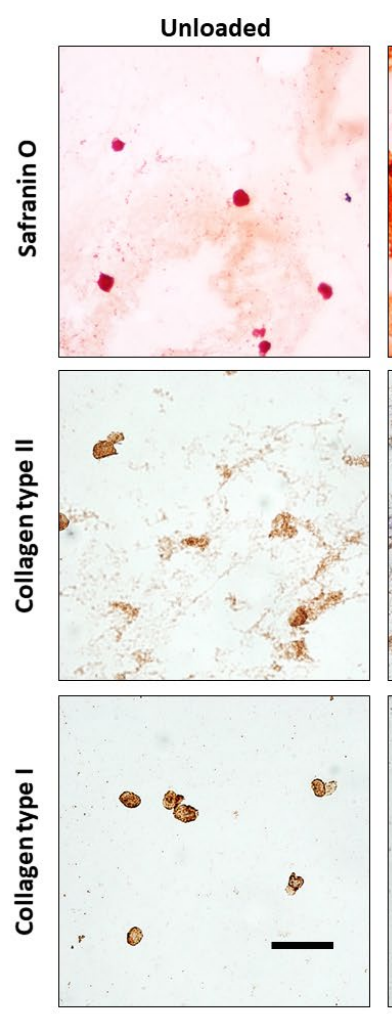

Post-loaded

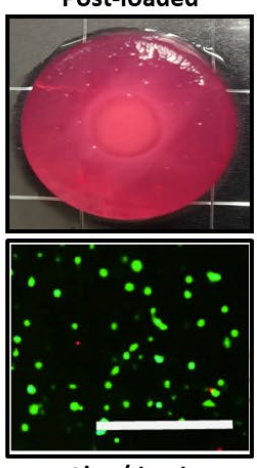

Live/dead

\section{C}
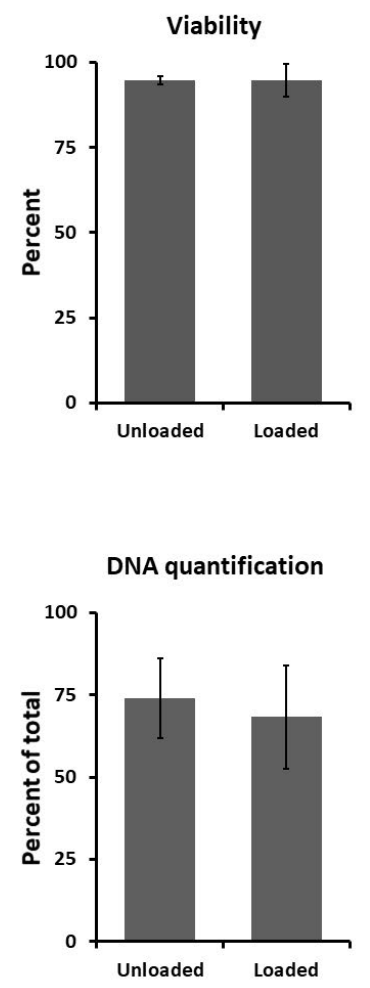

DMMB quantification

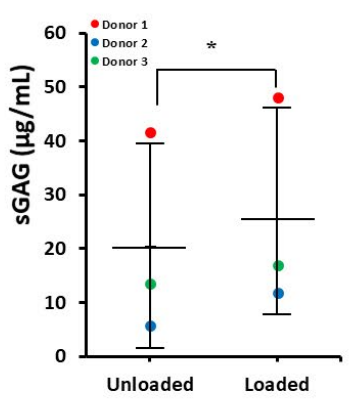

Fig. 5. Effects of physiological loading on human NP cells seeded in HA-pNIPAM hydrogel. (a) Representative images of a solidified cell-seeded hydrogel prior to agarose overlay and dynamic culture, a construct after 3 weeks of dynamic culture, the harvested gel from the construct and a LIVE/DEAD assay. Scale bar $=200 \mu \mathrm{m}$. (b) Representative images $(n=3)$ of immunohistochemistry and safranin O staining of cell-seeded gel sections, indicating more robust matrix deposition in loaded constructs when compared to unloaded controls. Scale bar $=100 \mu \mathrm{m}$. (c) Graphs showing quantified viability, extracted DNA and $\mathrm{DMMB}$ proteoglycan content as compared to initial cell seeding. Error bars represent mean $\pm \mathrm{SD}, n=3$. 
by $\mathrm{GuHCl}$, an equivalent amount of $0.4 \mathrm{M} \mathrm{GuHCl}$ was added to the standards. The Hoechst 33258 (Molecular Probes, ThermoFisher Scientific) was prepared according to the manufacturer instructions, along with serial dilutions of calf-thymus DNA (ThermoFisher Scientific). Samples were placed into 96-well Costar microplates in triplicate and assessed in Tecan M200 Pro plate reader, using $360 \mathrm{~nm}$ excitation, $460 \mathrm{~nm}$ emission and $420 \mathrm{~nm}$ cutoff. Standard curves were generated using Microsoft Excel.

Histological and immunohistochemistry analysis For the loaded and unloaded hydrogel constructs, harvested samples were fixed in $4 \%$ PLP, as

a
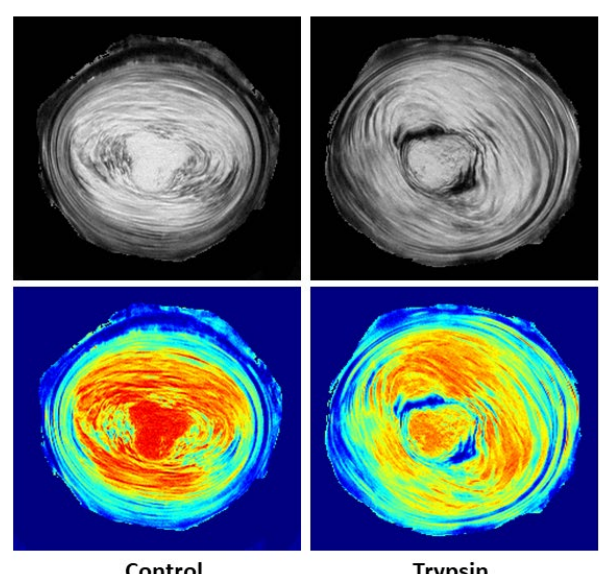

Control

Trypsin

b
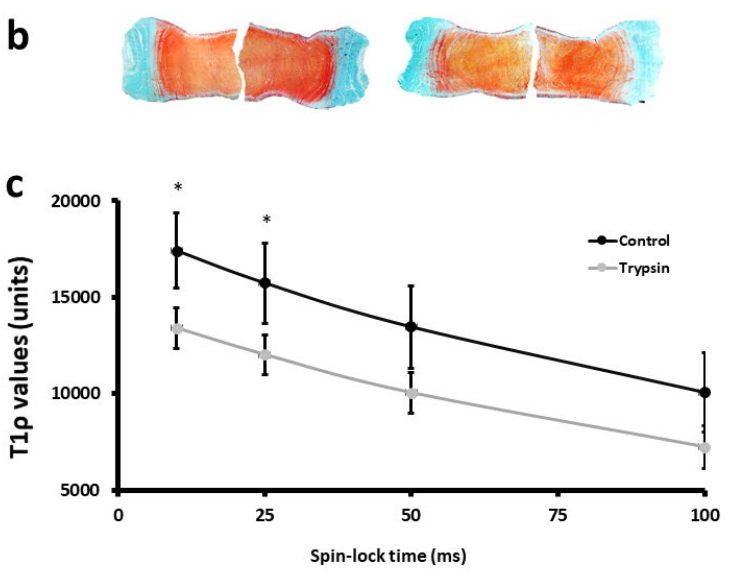

Fig. 6. T1@ mapping of isolated bovine caudal discs. (a) Representative images showing the central axial slice of a control disc and of a disc treated with trypsin to induce degeneration. The heat-map correlates the red colour with the highest and the blue colour with the lowest T1Q values. (b) Sections of the same disc stained with safranin $\mathrm{O} /$ fast green, indicating less proteoglycans in the trypsinised IVD. (c) T1@ mapping was performed for control and trypsinised IVDs at 10, 25, 50 and $100 \mathrm{~ms}$ spin-lock times and ROIs were selected over the entire NP region for quantification of relaxation times. Only the spin-lock times of 10 and $25 \mathrm{~ms}$ showed a significant difference in T1@ values between control and trypsinised NP regions $(n=4)$. described by Gawri et al. (2014a), for $24 \mathrm{~h}$ and, then, cryoprotected stepwise in $10 \%, 20 \%$ and $30 \%$ sucrose solutions. Next, samples were embedded in Tissue-Tek ${ }^{\circledR}$ O.C.T. compound and $5 \mu \mathrm{m}$ sections were cut and transferred onto Superfrost ${ }^{\circledR}$ Plus Micro Slide (VWR). Post-MRI analysis, intact IVD disc tissue was cut transversely using a custom tool, yielding $4 \mathrm{~mm}$-thick sections. Sections were fixed in PLP fixative overnight at $4^{\circ} \mathrm{C}$. Then, samples were washed in PBS and decalcified using Shandon ${ }^{\mathrm{TM}} \mathrm{TBD}^{\mathrm{TM}}$ Decalcifier solution (ThermoFischer Scientific) over $72 \mathrm{~h}$ at $4{ }^{\circ} \mathrm{C}$, changing solution each day. Tissues were washed in PBS and placed in $70 \%$ ethanol prior to paraffin embedding at the histology core facility. Sections of $5 \mu \mathrm{m}$ were cut and mounted on glass slides. All sections were heated on a hot plate at $55^{\circ} \mathrm{C}$ for $45 \mathrm{~min}$ and either deparaffinised and rehydrated (paraffin sections) or washed in PBS for 5 min (frozen sections). Next, sections were stained with safranin $\mathrm{O} /$ fast green (Sigma-Aldrich) and counter stained with Mayer's haematoxylin. Sections were also stained with antibodies against collagen type I (AB34710, 1 : 100; Abcam) and collagen type II (AB34712, $1: 500$; Abcam) and counter stained using the DAB kit (AB64262, mouse and rabbit; Abcam) following the manufacturer's instructions. All images were acquired using a Zeiss Axioskop 40 and an AxioCam MR (Zeiss) and processed using AxioVision LE64 software (Zeiss).

\section{Statistical analysis}

Statistical analysis was performed using Prism 6.0 software (GraphPad Software Inc., La Jolla, CA, USA). For all comparisons, one-way ANOVA followed by multiple comparisons post-hoc tests were performed. $p<0.05$ was considered statistically significant.

\section{Results}

In vitro evaluation of human NP-cells-seeded HApNIPAM

To determine the effects of dynamic loading on NP cell viability and matrix deposition when seeded in HA-pNIPAM, silicone/agarose constructs containing NP-cell-seeded HA-pNIPAM were either left unloaded or loaded dynamically for $21 \mathrm{~d}$ in the bioreactor. Following the culture period, each sample was either assayed for viability, had total protein/proteoglycan/DNA extracted or was fixed and cryoembedded for histological sectioning. LIVE/ DEAD analysis revealed approximately $95 \%$ NP cell viability in both loaded and unloaded conditions (Fig. $5 a, c)$. Total DNA analysis revealed no significant differences in total cell populations in loaded versus unloaded conditions (Fig. 5c). DMMB analysis revealed a significant increase in SGAG proteoglycan content in loaded samples (Fig. 5c). The actual amount varied among cells from individual donors; however, all significantly increased in response to loading. Histological assessment of the cultured 
constructs revealed proteoglycan deposition, as shown by safranin $\mathrm{O}$ staining. Dynamically cultured constructs had dramatically increased safranin $\mathrm{O}$ staining (Fig. 5b). Immunocytochemistry analysis revealed more collagen type II deposition in loaded constructs versus unloaded controls (Fig. 5b). No discernible difference in collagen type I deposition was observed between the two conditions (Fig. 5b).

T1Q MRI could detect quantifiable matrix differences in non-degenerate and degenerate isolated, intact intervertebral discs

T1Q-weighted MRI directly correlates with proteoglycan content in IVDs of intact human lumbar spine segments (Mulligan et al., 2014). To determine the degenerative status and potential zones of interest for cell/gel therapy, this MRI protocol was adapted to assess $\mathrm{T} 1 \varrho$ values in isolated, intact intervertebral discs. Healthy young or induced-degeneration (Gawri et al., 2014a) bovine caudal discs were scanned to determine whether T1@ relaxation maps could be used to detect significant differences between the two conditions. Bovine discs were used to save on precious human material and to ensure multiple discs of the same health status. MR images showed clear regions corresponding to proteoglycan loss (dark spots in NP region) (Fig. 6a). Safranin O/ fast green staining of histological sections of the same samples corroborated a loss of proteoglycan content in the induced-degeneration discs (Fig. 6b). Quantification of the T1@ values at varying spin-lock times reproducibly showed differences between healthy and degenerate NP tissues at 10 and $25 \mathrm{~ms}$ spin-lock time (Fig. 6c). These data indicated that T1@ MRI could be used to assess the proteoglycan content (i.e. health status) of the isolated, intact IVDs used.

Implantation of autologous NP cells seeded within HA-pNIPAM into intact and physiologically cultured human IVDs improved T1@ MRI scan values

Isolated, intact human lumbar IVDs were subjected to pre-treatment T1@ MRI scans across the axial and transverse planes. Discs were either injected with $\sim 400 \mu \mathrm{L}$ of HA-pNIPAM or $\sim 400 \mu \mathrm{L}$ of HA-pNIPAM seeded with $2 \times 10^{6}$ autologous NP cells $/ \mathrm{mL}$ of gel. The suspensions were injected into the central NP region. Implanted IVDs were cultured in the bioreactor under moderate dynamic loading conditions, as described by Rosenzweig et al. (2016b), for 5 weeks to allow for matrix production. Immediately following the culture, IVDs were subjected to T1@ MRI scans in the same orientation. Both gels alone and cell-seeded IVDs showed bright spots corresponding to the HApNIPAM in the post-treatment images as compared to the pre-treatment controls (Fig. 7a). ROIs of the same selected volume in each 'before' and 'after' culture image were analysed. Quantification of pre- versus post-treatment showed an increase of $11.2 \pm 6.9 \%$ $(p=0.067)$ in T1@ value for hydrogel alone, which was approaching statistical significance. For cellseeded hydrogel samples, there was a significant $13.2 \pm 6.2 \%(p=0.039)$ increase in T1Q values (Fig. $7 \mathbf{b})$ when comparing the post-treatment scan to the pre-treatment scans of the same disc in the same
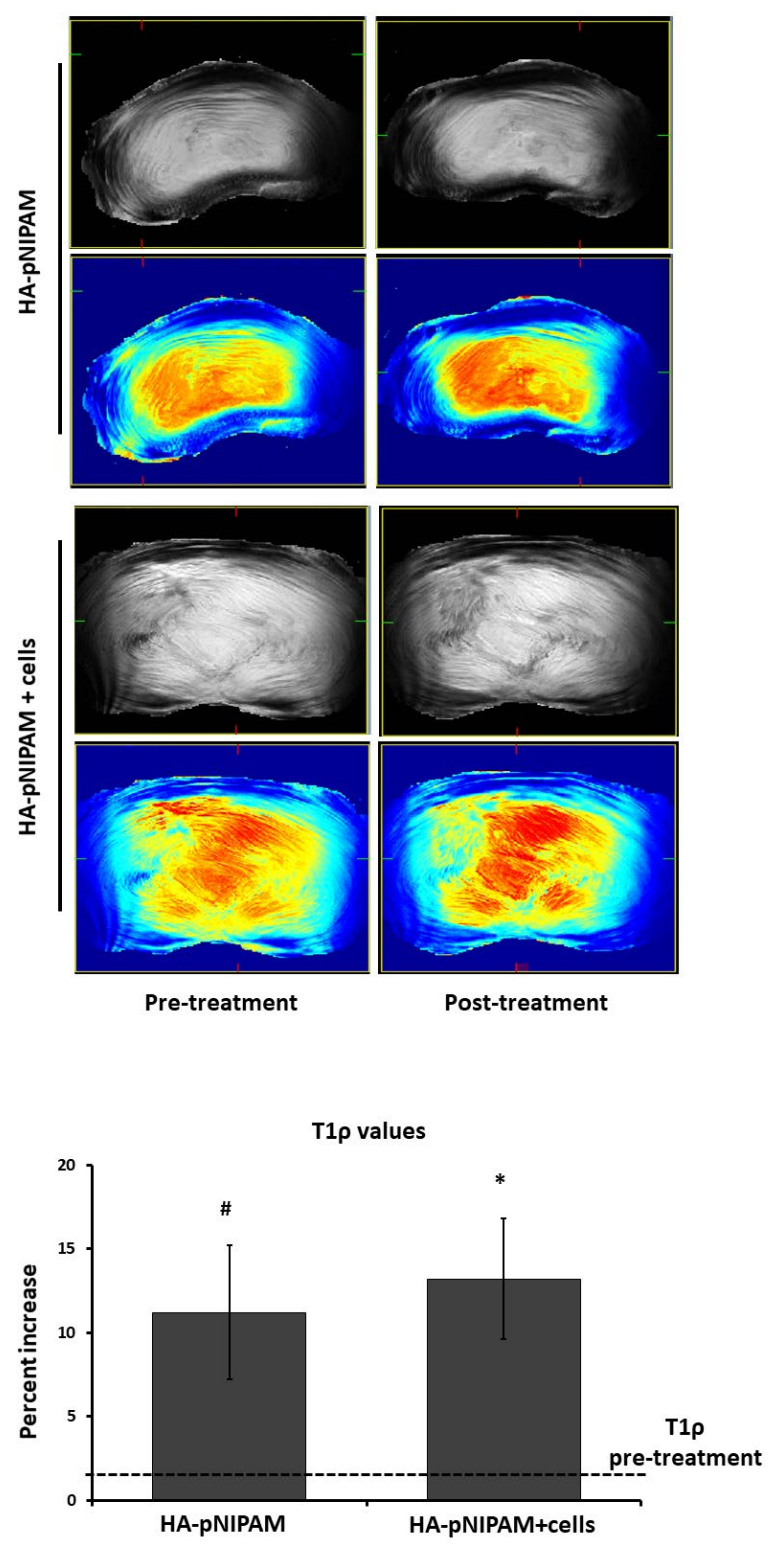

Fig. 7. T1@ imaging and quantification of pre- and post-implanted human IVDs. (a) Representative images of mid-axial T1e slices of pre-treated IVD and the same IVDs treated with either HA-pNIPAM alone or autologous NP-cell-seeded HA-pNIPAM, after 5 weeks of physiological culture. The heatmap correlates the red colour with the highest and the blue colour with the lowest T1Q values. All hydrogel regions were easily identified over 3-7 slices (out of 8). (b) Selected ROIs were copied from the post-treatment images and overlaid on the pre-treatment images for quantification with the graph showing percentage increase in T1@ values in gel alone and cell-seeded gel treatments when compared to the pre-treatment $\mathrm{T} 1 \mathrm{Q}$ values. Error bars represent mean $\pm S D, n=3$ for each condition. 
ROIs. When comparing the discs that were treated with gel alone or with cell-seeded gel, there was no significant difference in T1@ values after the 5 weeks of culture $(p=0.376)$. Taken into the context of a previous study by Mulligan et al. (2014), this result indicated that treatment of human IVDs with autologous NP-cell-seeded HA-pNIPAM (and to some degree, HA-pNIPAM alone) increased the T1@ values within those specific ROIs following 5 weeks of dynamic culture.

The bioreactor system assessed load displacement data over the duration of the 5 weeks culture. From these data, mechanical properties of the tissues could be determined. Upon assessment of the displacement curves, no difference in load curves for the hydrogel alone and cell-seeded hydrogel discs were found (Fig. 8a). It was evident from the load curves that the IVDs responded to load in the same way as mildly degenerated discs do (Rosenzweig et al., 2016b). The stable cyclical loss and gain in height from all treated discs indicated that hydrogel injection did not cause any undesirable effects and tissue stability was preserved following injection of gel alone or cellseeded hydrogel.

Implantation of autologous NP cells seeded within HA-pNIPAM into intact and physiologically cultured human IVDs promoted tissue repair and regeneration

To verify that the increased MRI signal corresponded to proteoglycan content, histological and immunohistological evaluation of the treated human IVDs were performed. Safranin O staining consistently showed high levels of proteoglycan

a
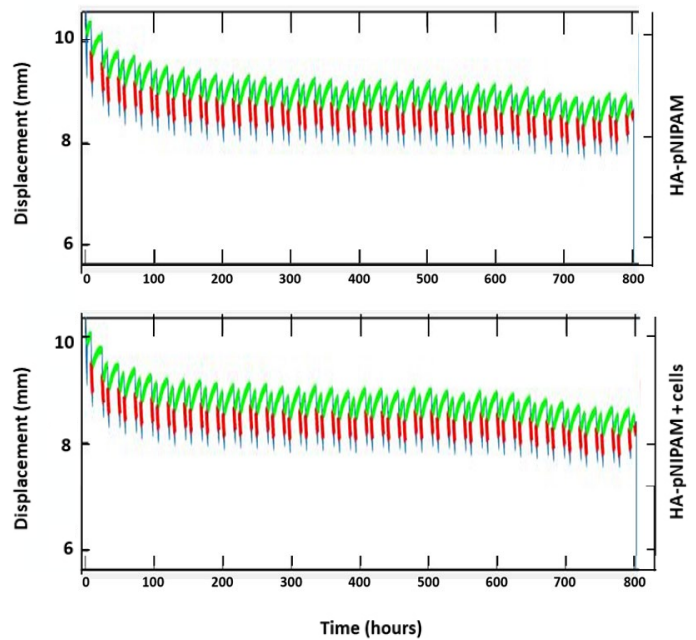

deposition within identified hydrogel regions of the IVDs injected with HA-pNIPAM alone (Fig. 8b), likely accumulated from surrounding native cells/ tissue since hydrogel alone had faint background staining (data not shown). All samples injected with NP-cell-seeded HA-pNIPAM also showed intense proteoglycan deposition in the identified hydrogel regions (Fig. 8b). To maintain optimal bioactivity of the autologous NP cells, a tracker for the implanted cells was not used. For IVDs implanted with gel alone, haematoxylin staining showed no evidence of cells within the empty gel after 5 weeks in culture. However, cell-seeded hydrogels showed evidence of remodelling and neo-tissue production around the implanted cells as well, which were abundantly evident by haematoxylin staining. These cells were likely those that were introduced by implantation. Immunohistochemical assessment of the main NP matrix marker, collagen type II, showed high levels of positive staining in NP-cell-seeded hydrogels (Fig. 9). Collagen type II staining was not observed in hydrogel regions where HA-pNIPAM alone was implanted. Collagen type I was not detected in the cell-seeded hydrogels or hydrogels alone in any of the implanted IVDs. These data suggested that autologous NP cells seeded within the hydrogel responded to 5 weeks of physiological, dynamic culture by producing NP-like matrix.

\section{Discussion}

Constant improvements in tissue engineering strategies have resulted in the generation of several

b
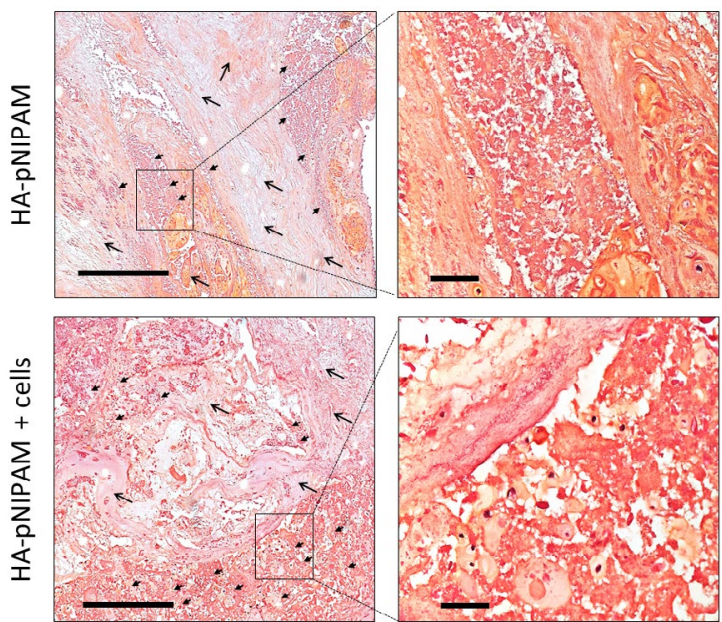

Fig. 8. Effect of treatments on disc height change and proteoglycan deposition. (a) Representative load curves for IVDs treated with gel alone or cell-seeded gel, showing no major changes in disc height throughout the experiments. The load curves represent the $2 \mathrm{~h}$ dynamic, $6 \mathrm{~h}$ static, $2 \mathrm{~h}$ dynamic and $14 \mathrm{~h}$ static cycles over the $35 \mathrm{~d}$ culture period. Red portions of the curves represent the $2 \mathrm{~h}$ cyclic loading where discs lose height. The first shorter green portion of the curves represents the $6 \mathrm{~h}$ static period where some height is regained. The following longer green portion represents each $14 \mathrm{~h}$ static rest period where more disc height is regained. (b) Representative safranin $\mathrm{O} /$ fast green staining of histological sections. Hydrogel alone accumulated proteoglycan; however, cell-seeded hydrogel showed evidence of neo-matrix deposition within the gel area, $n=3$ for each condition. Larger scale bar on $10 \times$ images $=250 \mu \mathrm{m}$; smaller scale bar on $40 \times$ images $=50 \mu \mathrm{m}$. 


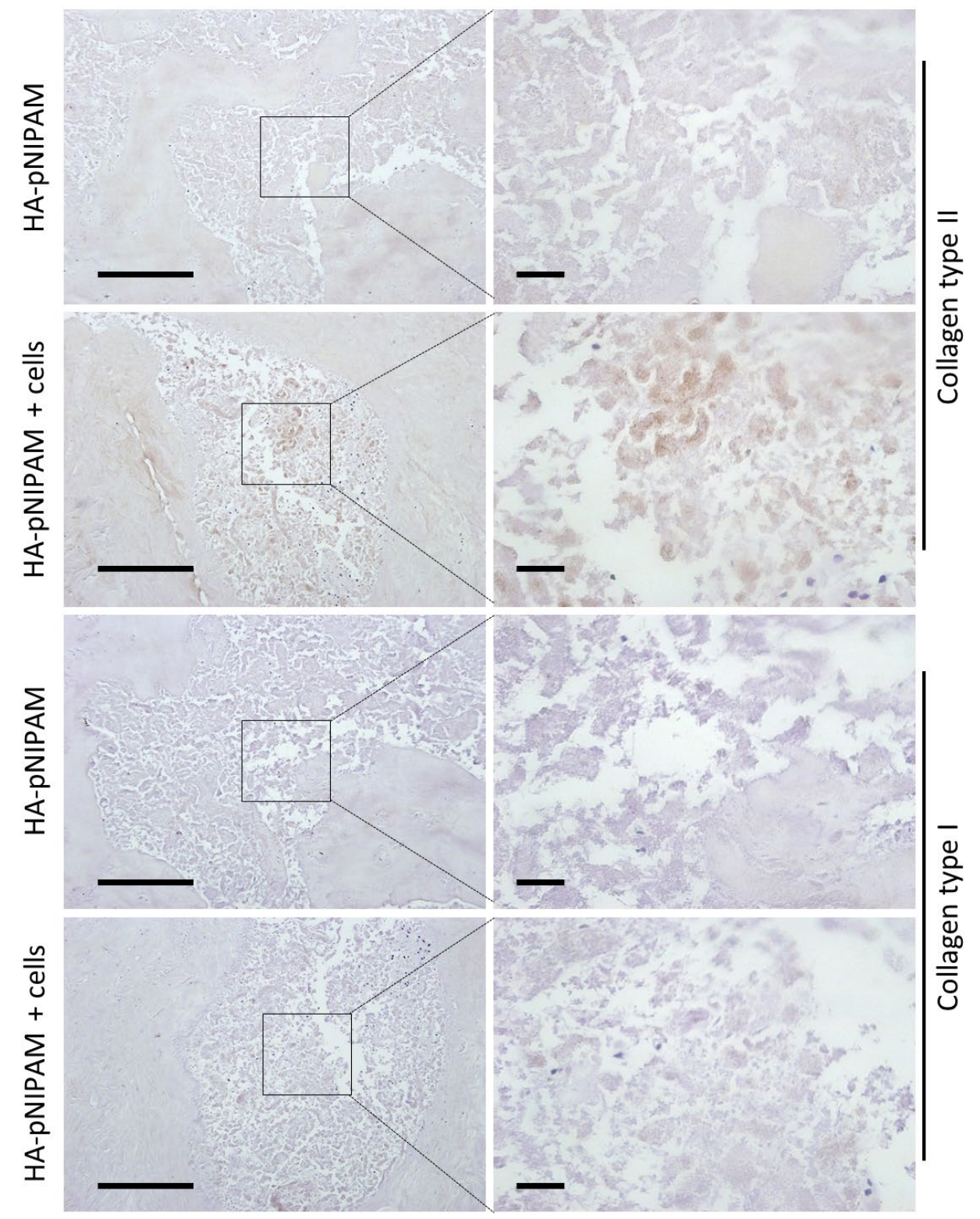

Fig. 9. Effect of treatments on collagen types I and II deposition. Representative collagen type II and collagen type I immunohistochemical staining of sections. Hydrogel alone showed little evidence of collagen type II accumulation and no evidence of collagen type I. However, cell-seeded hydrogel showed strong evidence of collagen type II deposition within hydrogel regions and no evidence of collagen type I, $n=3$ for each condition. Larger scale bar on $10 \times$ images $=250 \mu \mathrm{m}$; smaller scale bar on $40 \times$ images $=50 \mu \mathrm{m}$.

useful hydrogel carriers for applying cell-based therapeutics in both in vitro and in vivo pre-clinical studies. The hydrogels can serve to protect implanted cells from the often-harsh environments in which they are placed. Hydrogels also serve to fill small tissue fissures, further supporting the implanted cells (Peroglio et al., 2013; Rosenzweig et al., 2016b). A bioreactor system for long-term physiological culture of intact human discs is developed by Rosenzweig et al. (2016b) showing that this culture system can support studies on NP cell delivery within an HA-pNIPAM carrier. However, it is not possible to determine the effects of dynamic loading on NP cells within the HA-pNIPAM nor to establish the degenerative status of those tissues prior to cell implantation (Rosenzweig et al., 2016b). As such, tissue repair in those experiments is not fully assessed. In the present study, a previously established T1@ MRI sequence (Mulligan et al., 2014) was adapted to assess the proteoglycan content in the isolated discs before and after cell/gel implantation. Use of this specific imaging modality allowed both the identification of degenerative hot-spots in which to direct the implantation and the non-invasive quantification of tissue repair through proteoglycan content. The present study demonstrated that i) dynamic physiological loading drove disc-like matrix deposition by isolated human NP cells in vitro; ii) HA-pNIPAM alone enhanced T1e values in physiologically cultured intact human IVD; iii) implanted autologous NP-cell-seeded HA-pNIPAM significantly enhanced T1@ values, promoted tissue 
regeneration and NP-like matrix deposition in intact human IVDs after 5 weeks of dynamic culture. Taken together, these data suggested a strong potential for minimally invasive delivery of cell-seeded HA-pNIPAM for matrix restoration in early-stage degenerative IVDs.

In the present study, autologous NP cells isolated from non-degenerate adjacent-level discs were applied for gel-seeding and delivery. This served as a gold standard of tissue repair to which any cell therapy should aspire, as there is no benign site for autologous NP cell isolation from patients with low back pain and early disc degeneration (Mochida et al., 2015; Rosenzweig et al., 2017). Over the past decade, three studies have tested the clinical efficacy of bonemarrow-derived MSCs for IVD repair. Yoshikawa et al. (2010) show that implantation of approximately 500,000 autologous MSCs seeded in collagen sponges into the IVD can improve T2 MRI, reduce instability and alleviate pain symptoms in two patients. Orozco et al. (2011) directly inject approximately 5-10 million autologous bone-marrow-derived MSCs into the $\mathrm{NP}$, immediately alleviating pain and disability in ten patients and improving T2 MRI but not disc height. Noriega et al. (2017) show in a randomised controlled study that direct implantation of 25 million allogeneic bone-marrow-derived MSCs is safe, can alleviate pain and improved Pfirrmann MRI scores. In another cell-based therapy clinical study, 15 patients are directly injected with 10 million juvenile allogeneic chondrocytes into the NP region of their degenerate discs, which results in improved MRI and pain scores (Coric et al., 2013). While many of these studies do not show improved disc height, MSCs clearly hold the potential to improve proteoglycan content in the ECM and relieve pain. Applying MSCs within the HA-pNIPAM carrier may further improve treatment by protecting transplanted cells and filling and populating cavities in the IVD. This might also improve the biomechanical properties of the IVD.

Mochida et al. (2015) implant 1 million autologous NP cells which are activated in co-culture with MSCs into Pfirrmann grade 3 discs adjacent to site of lumbar fusion. Patients show only slight improvement in T2 MRI and present no pain in a 3-year follow-up (Mochida et al., 2015). The present study showed that implanting autologous NP cells seeded within an HA-pNIPAM hydrogel significantly improved T1@ MRI, which directly correlated with increased proteoglycan content in isolated human IVDs under dynamic culture conditions. This was probably due to the hydrogel carrier, which could fill every fissure in the NP, thereby potentially providing support for the implanted cells until they built enough matrix to get incorporated into the native tissue. This idea was supported by the in vitro results. It is important to re-emphasise that no benign site for NP cell isolation exists and, therefore, MSCs remain the best choice for clinical applications in cell-based therapy for disc repair. However, it remains to be determined if un-differentiated or pre-differentiated MSCs would give the most favourable results.

The variation of hydrogel used in the present study was HA linked to a thermoreversible pNIPAM polymer. HA is one of the major extracellular matrix components. This abundant polysaccharide is ubiquitous and, in IVDs, it interacts mainly with the proteoglycan aggrecan to promote tissue hydration and resistance to compression (Laurent et al., 1996; Roughley et al., 2006; Urban and Roberts, 2003). The HA-pNIPAM formulation is previously described for its suitability as a cell therapy carrier (Mortisen et al., 2010). In addition, it is suitable for encapsulation of bovine NP cell (Peroglio et al., 2012) and human MSCs (Peroglio et al., 2013), thus promoting proteoglycan production and gene expression reflecting the native tissue. The bovine NP- and human MSC-seeded hydrogels were also able to be implanted into an $e x$ vivo bovine disc organ culture where cells produce NP-like ECM (Peroglio et al., 2012). Furthermore, human NP cells encapsulated in the HA-pNIPAM can be implanted into intact human IVDs ex vivo, where they remain viable for $10 \mathrm{~d}$ in dynamic culture using a cell-labelled tracking method (Rosenzweig et al., 2016b). The present study showed high levels of NP cell viability and matrix production in vitro after $21 \mathrm{~d}$ of dynamic culture. Furthermore, human IVDs implanted with the cell-seeded hydrogels showed significantly increased T1e values and evidence of neo-tissue production while the gel alone did not. This suggested that the implanted cells remained viable and biologically active after implantation and dynamic culture for 5 weeks. Also, implantation process through a syringe with a $25 \mathrm{G}$ needle did not affect the biomechanics of the implanted discs, since the cyclical loss and regain of disc height shown in the load curves remained stable throughout the 5 week dynamic culture period.

In addition to the present study, only Thorpe et al. (2016) show a strong potential for cell-based therapy using a pNIPAM-based hydrogel. They use a pNIPAM variation, pNIPAM-DMAc-Laponite, which is liquid at $39{ }^{\circ} \mathrm{C}$ and gels at $37{ }^{\circ} \mathrm{C}$. This hydrogel strongly promotes NP-like differentiation and matrix deposition by seeded MSCs; however, this is seemingly dependent on low oxygen tension. In the present study in vitro experiments, NP-seeded HA-pNIPAM produced plenty of NP-like matrix deposition in regular tissue culture conditions. One major difference is the carrier gelation modality: in the present study, HA-pNIPAM was fluid at room temperature and solidified upon injection (above $\left.32{ }^{\circ} \mathrm{C}\right)$, whereas the system used by Thorpe et al. (2016) is fluid above $39{ }^{\circ} \mathrm{C}$ and solidifies at lower temperatures, similarly to gelatine. The necessity of pre-heating the gel before and during administration is a possible limitation towards its clinical translation. Another important difference between the studies is the cell type used. Fully differentiated NP cells, which optimally produce NP matrix, were used in 
the present study, whereas Thorpe et al. (2016) use un-differentiated MSCs. In a follow-up study, Thorpe et al. (2017) implant MSC-seeded pNIPAM-DMAcLaponite into artificially induced degenerate bovine IVDs. After 6 weeks of culture in low oxygen and unloaded conditions, disc mechanical properties are restored, the gel is incorporated into the native tissue and proteoglycan and collagen type II are produced by the implanted cells (Thorpe et al., 2017). In the present study, gel incorporation into the native human disc tissue was found as well, as evidenced by MRI analysis, and when NP cells were seeded into the HA-pNIPAM, tissue regeneration was strongly evident by histological analysis. Cultures were carried out under dynamic loading conditions for 5 weeks and it was likely the physiological loading which drove matrix and tissue formation, as suggested by the in vitro data comparing loaded with unloaded cell-seeded hydrogels and a study by Gawri et al. (2014a). When taken together, the study's data strongly supported the use of cell-seeded HApNIPAM for human disc repair applications.

To determine the regenerative effects of cells, biological and tissue engineering therapies of IVDs, long-term culture in bioreactor is often employed (Gantenbein et al., 2015). Culture models are developed where whole intact IVDs can be cultured long-term under physiological loading conditions (Chan et al., 2011; Haglund et al., 2011; Junger et al., 2009; Paul et al., 2013; Rosenzweig et al., 2016b; Walter et al., 2014). Such a culture system is ideal for assessing the effects of dynamic loading on human disc cells (or any other cell type) suspended in hydrogels such as the HA-pNIPAM used in the present study. The bioreactor was modified to allow culture of agarose-encased cell-seeded hydrogels by surrounding the construct with a silicone tubing. The tubing could distribute the applied load, while the agarose/gel construct underwent physiologically relevant $10 \%$ cyclic compressive strain. The model further simulated the native disc by allowing nutrient and waste diffusion into and out of the construct from the top and bottom only. Once the appropriate loading for cell-seeded HA-pNIPAM was determined, the cell-seeded gels could be implanted into the established human IVD culture system. A large improvement over the previous two human IVD culture studies (Rosenzweig et al., 2016b; Walter et al., 2014) was obtained since autologous NP cell delivery within the HA-pNIPAM carrier significantly enhanced matrix replenishment in human IVDs (i.e. improved T1@ MRI and proteoglycan and collagen histological assessment following 5 weeks of dynamic physiological culture). Discs injected with hydrogel alone also showed slightly improved MRI signal and retention of proteoglycan. This is in accordance with another study showing that hydrogels alone can improve mechanical function of induceddegenerative discs (Zhou et al., 2014). Combined with the results of the cell-based IVD repair clinical studies
(Mochida et al., 2015; Noriega et al., 2017; Orozco eet al., 2011), the present study suggested that adding a hydrogel cell carrier might further improve tissue repair by increasing NP proteoglycan content in a quantifiable manner. However, assessing the repair potential of cell delivery or the hydrogel itself requires a non-invasive approach to determine the donor disc matrix composition prior to implantation and final assessment. To the best of our knowledge, there is no proven method for performing high-resolution imaging of isolated intact IVDs, to determine efficacy of therapeutics pre- and post-treatment.

The ability to non-invasively assess the degenerative state of an IVD prior to any treatment is imperative for determining whether treatments are repairing and regenerating the tissue. While Pfirrmann scoring of IVDs using T2-weighted MRI is the standard clinical assessment for degenerative disc disease (Pfirrmann et al., 2001), it identifies mainly the water/hydration content of the tissue. T1@ MRI offers an alternative sequence that is directly correlated with proteoglycan content, allowing for quantitation of early disc degeneration (Wang et al., 2007; Zobel et al., 2012). An axial T1@ MRI mapping sequence is developed by Mulligan et al. (2014) using cadaveric lumbar spine segments and matching, in the same sample, mapping and biochemical proteoglycan quantification. This pulse sequence was expanded adapting it towards isolated, intact bovine and human IVDs. The T1@ images were of very high quality, showing hot-spot regions within the NP where implantation treatments could be directed. Indeed, follow-up MRI and histological analysis revealed that the hydrogel infiltrated all tissue fissures and empty spaces within reach. In all, the T1@ MRI developed for IVD explants is of great value for researchers studying IVD repair and regeneration using organ culture methods not only for identifying target regions for repair, but also for non-invasively quantifying tissue repair.

In summary, T1@ MRI was adapted for noninvasively assessing degenerative status of isolated, intact human IVDs pre- and post-treatment with hydrogel/cell therapy. A thermoresponsive HApNIPAM hydrogel was used to deliver autologous human NP cells which, seemingly, regenerated intact human IVDs in a long-term dynamic, physiological bioreactor culture system. Isolated, autologous NP cells optimally produced NP matrix, therefore being a gold standard to which stem cell-based therapies should aspire. Since MSCs are most commonly used in ongoing clinical applications, future studies will compare the repair potential of HA-pNIPAM seeded with human adipose and bone-marrow-derived MSCs in the human disc dynamic culture system. In future studies, this system will serve as a screening platform to test efficacy of potential therapeutics in living human IVDs, thereby, providing insights prior to engaging in in vivo animal studies. 


\section{Acknowledgements}

This work was supported by the Canadian Institutes of Health Research (CIHR) grant CIHR MOP119564 and AOSpine, SRN_2011_04_10498. We thank Dr Peter J. Roughley for valuable discussions of the presented work. We also thank the RSBO for histological services. DHR, RF, APM and LL conducted experiments, analysed data, interpreted results and wrote the first manuscript draft. APM oversaw and conducted all MRI scans and DHR and APM analysed and interpreted the data. JAO and MHW were responsible for the spine harvesting from organ donors. JAO, TS and MHW contributed to the design of the study, interpreted the results and reviewed and revised the manuscript. MDE and DE provided the HA-pNIPAM formulation, ensured batch consistency, provided training on handling the hydrogel, interpreted the results and reviewed and revised the manuscript. DHR, TS, DE and LH designed the study. LH interpreted the results, managed and coordinated the overall project and wrote the manuscript. All authors approved the final manuscript.

\section{Disclosures}

The authors confirm that there are no known conflicts of interest associated with this publication and there has been no significant financial support for this work that could have influenced its outcome.

\section{References}

Adams MA, Lama P, Zehra U, Dolan P (2014) Why do some intervertebral discs degenerate, when others (in the same spine) do not? Clin Anat 28: 195-204.

Adams MA, Roughley PJ (2006) What is intervertebral disc degeneration, and what causes it? Spine 31: 2151-2161.

Alkhatib B, Rosenzweig DH, Krock E, Roughley PJ, Beckman L, Steffen T, Weber MH, Ouellet JA, Haglund L (2014) Acute mechanical injury of the human intervertebral disc: link to degeneration and pain. Eur Cell Mater 28: 98-111.

Bailey JF, Miller SL, Khieu K, O'Neill CW, Healey RM, Coughlin DG, Sayson JV, Chang DG, Hargens AR, Lotz JC (2017) From the international space station to the clinic: how prolonged unloading may disrupt lumbar spine stability. Spine J 8: 7-14.

Borthakur A, Hulvershorn J, Gualtieri E, Wheaton AJ, Charagundla S, Elliott MA, Reddy R (2006a) A pulse sequence for rapid in vivo spin-locked MRI. J Magn Reson Imaging 23: 591-596.

Borthakur A, Mellon E, Niyogi S, Witschey W, Kneeland JB, Reddy R (2006b) Sodium and T1rho MRI for molecular and diagnostic imaging of articular cartilage. NMR Biomed 19: 781-821.
Burdick JA, Mauck RL, Gerecht S (2016) To serve and protect: hydrogels to improve stem cell-based therapies. Cell Stem Cell 18: 13-15.

Chan SC, Ferguson SJ, Gantenbein-Ritter B (2011) The effects of dynamic loading on the intervertebral disc. Eur Spine J 20: 1796-1812.

Coric D, Pettine K, Sumich A, Boltes MO (2013) Prospective study of disc repair with allogeneic chondrocytes presented at the 2012 Joint Spine Section Meeting. J Neurosurg Spine 18: 85-95.

D'Este M, Alini M, Eglin D (2012) Single step synthesis and characterization of thermoresponsive hyaluronan hydrogels. Carbohydr Polym 90: 13781385.

D'Este M, Sprecher CM, Milz S, Nehrbass D, Dresing I, Zeiter S, Alini M, Eglin D (2016) Evaluation of an injectable thermoresponsive hyaluronan hydrogel in a rabbit osteochondral defect model. J Biomed Mater Res A 104: 1469-1478.

de Vries-van Melle ML, Tihaya MS, Kops N, Koevoet WJ, Murphy JM, Verhaar JA, Alini M, Eglin D, van Osch GJ (2014) Chondrogenic differentiation of human bone marrow-derived mesenchymal stem cells in a simulated osteochondral environment is hydrogel dependent. Eur Cell Mater 27: 112-123.

Gantenbein B, Illien-Junger S, Chan SC, Walser J, Haglund L, Ferguson SJ, Iatridis JC, Grad S (2015) Organ culture bioreactors - platforms to study human intervertebral disc degeneration and regenerative therapy. Curr Stem Cell Res Ther 10: 339-352.

Gawri R, Moir J, Ouellet J, Beckman L, Steffen T, Roughley P, Haglund L (2014a) Physiological loading can restore the proteoglycan content in a model of early IVD degeneration. PLoS One 9: e101233.

Gawri R, Mwale F, Ouellet J, Roughley PJ, Steffen T, Antoniou J, Haglund L (2011) Development of an organ culture system for long-term survival of the intact human intervertebral disc. Spine (Phila Pa 1976) 36: 1835-1842.

Gawri R, Rosenzweig DH, Krock E, Ouellet JA, Stone LS, Quinn TM, Haglund L (2014b) High mechanical strain of primary intervertebral disc cells promotes secretion of inflammatory factors associated with disc degeneration and pain. Arthritis Res Ther 16: R21.

Haglund L, Moir J, Beckman L, Mulligan KR, Jim B, Ouellet JA, Roughley P, Steffen T (2011) Development of a bioreactor for axially loaded intervertebral disc organ culture. Tissue Eng Part C Methods 17: 1011-1019.

Hoemann CD (2004) Molecular and biochemical assays of cartilage components. Methods Mol Med 101: 127-156.

Holm S, Maroudas A, Urban JP, Selstam G, Nachemson A (1981) Nutrition of the intervertebral disc: solute transport and metabolism. Connect Tissue Res 8: 101-119.

Humzah MD, Soames RW (1988) Human intervertebral disc: structure and function. Anat Rec 220: 337-356. 
Jim B, Steffen T, Moir J, Roughley P, Haglund L (2011) Development of an intact intervertebral disc organ culture system in which degeneration can be induced as a prelude to studying repair potential. Eur Spine J 20: 1244-1254.

Junger S, Gantenbein-Ritter B, Lezuo P, Alini M, Ferguson SJ, Ito K (2009) Effect of limited nutrition on in situ intervertebral disc cells under simulatedphysiological loading. Spine (Phila Pa 1976) 34: 12641271.

Karppinen J, Shen FH, Luk KDK, Andersson GBJ, Cheung KMC, Samartzis D (2011) Management of degenerative disk disease and chronic low back pain. Orthop Clin North Am 42: 513-528.

Krock E, Rosenzweig DH, Currie JB, Bisson DG, Ouellet JA, Haglund L (2017) Toll-like receptor activation induces degeneration of human intervertebral discs. Sci Rep 7: 17184.

Laurent TC, Laurent UB, Fraser JR (1996) The structure and function of hyaluronan: an overview. Immunol Cell Biol 74: A1-7.

MacLean JJ, Roughley PJ, Monsey RD, Alini M, Iatridis JC (2008) In vivo intervertebral disc remodeling: kinetics of mRNA expression in response to a single loading event. J Orthop Res 26: 579-588.

Marchand F, Ahmed AM (1990) Investigation of the laminate structure of lumbar disc anulus fibrosus. Spine (Phila Pa 1976) 15: 402-410.

McNally DS, Adams MA (1992) Internal intervertebral disc mechanics as revealed by stress profilometry. Spine (Phila Pa 1976) 17: 66-73.

Mochida J, Sakai D, Nakamura Y, Watanabe T, Yamamoto Y, Kato S (2015) Intervertebral disc repair with activated nucleus pulposus cell transplantation: a three-year, prospective clinical study of its safety. Eur Cell Mater 29: 202-212.

Mort JS, Roughley PJ (2007) Measurement of glycosaminoglycan release from cartilage explants. Methods Mol Med 135: 201-209.

Mortisen D, Peroglio M, Alini M, Eglin D (2010) Tailoring thermoreversible hyaluronan hydrogels by "click" chemistry and RAFT polymerization for cell and drug therapy. Biomacromolecules 11: 1261-1272.

Mulligan KR, Ferland CE, Gawri R, Borthakur A, Haglund L, Ouellet JA (2014) Axial T1rho MRI as a diagnostic imaging modality to quantify proteoglycan concentration in degenerative disc disease. Eur Spine J 24: 2395-401.

Nachemson A (1960) Lumbar intradiscal pressure. Experimental studies on post-mortem material. Acta Orthop Scand Suppl 43: 1-104.

Nachemson A (1975) Towards a better understanding of low-back pain: a review of the mechanics of the lumbar disc. Rheumatol Rehabil 14: 129-143.

Noriega DC, Ardura F, Hernandez-Ramajo R, Martin-Ferrero MA, Sanchez-Lite I, Toribio B, Alberca M, Garcia V, Moraleda JM, Sanchez A, Garcia-Sancho J (2017) Intervertebral disc repair by allogeneic mesenchymal bone marrow cells: a randomized controlled trial. Transplantation 101: 1945-1951.
Orozco L, Soler R, Morera C, Alberca M, Sanchez A, Garcia-Sancho J (2011) Intervertebral disc repair by autologous mesenchymal bone marrow cells: a pilot study. Transplantation 92: 822-828.

Paul CP, Schoorl T, Zuiderbaan HA, Zandieh Doulabi B, van der Veen AJ, van de Ven PM, Smit TH, van Royen BJ, Helder MN, Mullender MG (2013) Dynamic and static overloading induce early degenerative processes in caprine lumbar intervertebral discs. PLoS One 8: e62411.

Paul CP, Zuiderbaan HA, Zandieh Doulabi B, van der Veen AJ, van de Ven PM, Smit TH, Helder MN, van Royen BJ, Mullender MG (2012) Simulatedphysiological loading conditions preserve biological and mechanical properties of caprine lumbar intervertebral discs in ex vivo culture. PLoS One 7: e33147.

Peroglio M, Eglin D, Benneker LM, Alini M, Grad S (2013) Thermoreversible hyaluronan-based hydrogel supports in vitro and ex vivo disc-like differentiation of human mesenchymal stem cells. Spine J 13: 16271639.

Peroglio M, Grad S, Mortisen D, Sprecher CM, Illien-Junger S, Alini M, Eglin D (2012) Injectable thermoreversible hyaluronan-based hydrogels for nucleus pulposus cell encapsulation. Eur Spine J 21 Suppl 6: S839-849.

Pfirrmann CW, Metzdorf A, Zanetti M, Hodler J, Boos N (2001) Magnetic resonance classification of lumbar intervertebral disc degeneration. Spine (Phila Pa 1976) 26: 1873-1878.

Quint U, Wilke HJ (2008) Grading of degenerative disk disease and functional impairment: imaging versus patho-anatomical findings. Eur Spine J 17: 1705-1713.

Ract I, Meadeb JM, Mercy G, Cueff F, Husson JL, Guillin R (2015) A review of the value of MRI signs in low back pain. Diagn Interv Imaging 96: 239-249.

Rosenzweig DH, Gawri R, Moir J, Beckman L, Eglin D, Steffen T, Roughley PJ, Ouellet JA, Haglund L (2016a) Dynamic loading, matrix maintenance and cell injection therapy of human intervertebral discs cultured in a bioreactor. Eur Cell Mater 31: 26-39.

Rosenzweig DH, Gawri R, Moir J, Beckman L, Eglin D, Steffen T, Roughley PJ, Ouellet JA, Haglund L (2016b) Dynamic loading, matrix maintenance and cell injection therapy of human intervertebral discs cultured in a bioreactor. Eur Cell Mater 30: 26-39.

Rosenzweig DH, Tremblay Gravel J, Bisson D, Ouellet JA, Weber MH, Haglund L (2017) Comparative analysis in continuous expansion of bovine and human primary nucleus pulposus cells for tissue repair applications. Eur Cell Mater 33: 240251.

Roughley PJ (2004) Biology of intervertebral disc aging and degeneration: involvement of the extracellular matrix. Spine 29: 2691-2699.

Roughley PJ, Melching LI, Heathfield TF, Pearce RH, Mort JS (2006) The structure and degradation of aggrecan in human intervertebral disc. Eur Spine J 15 Suppl 3: S326-332. 
Sakai D, Andersson GBJ (2015) Stem cell therapy for intervertebral disc regeneration: obstacles and solutions. Nat Rev Rheumatol 11: 243-256.

Sakai D, Grad S (2015) Advancing the cellular and molecular therapy for intervertebral disc disease. Adv Drug Deliv Rev 84: 159-171.

Sivan SS, Tsitron E, Wachtel E, Roughley PJ, Sakkee N, van der Ham F, DeGroot J, Roberts S, Maroudas A (2006) Aggrecan turnover in human intervertebral disc as determined by the racemization of aspartic acid. J Biol Chem 281: 13009-13014.

Sivan SS, Wachtel E, Tsitron E, Sakkee N, van der Ham F, Degroot J, Roberts S, Maroudas A (2008) Collagen turnover in normal and degenerate human intervertebral discs as determined by the racemization of aspartic acid. J Biol Chem 283: 87968801.

Thorpe AA, Boyes VL, Sammon C, Le Maitre CL (2016) Thermally triggered injectable hydrogel, which induces mesenchymal stem cell differentiation to nucleus pulposus cells: potential for regeneration of the intervertebral disc. Acta Biomater 36: 99-111.

Thorpe AA, Dougill G, Vickers L, Reeves ND, Sammon C, Cooper G, Le Maitre CL (2017) Thermally triggered hydrogel injection into bovine intervertebral disc tissue explants induces differentiation of mesenchymal stem cells and restores mechanical function. Acta Biomater 54: 212-226.

Tobert DG, Antoci V, Patel SP, Saadat E, Bono CM (2017) Adjacent segment disease in the cervical and lumbar spine. Clin Spine Surg 30: 94-101.

Urban JP, Roberts S (2003) Degeneration of the intervertebral disc. Arthritis Res Ther 5: 120-130.

Walter BA, Illien-Junger S, Nasser PR, Hecht AC, Iatridis JC (2014) Development and validation of a bioreactor system for dynamic loading and mechanical characterization of whole human intervertebral discs in organ culture. J Biomech 47: 2095-2101.

Walter BA, Korecki CL, Purmessur D, Roughley PJ, Michalek AJ, Iatridis JC (2011) Complex loading affects intervertebral disc mechanics and biology. Osteoarthritis Cartilage 19: 1011-1018.

Wang C, Auerbach JD, Witschey WR, Balderston RA, Reddy R, Borthakur A (2007) Advances in magnetic resonance imaging for the assessment of degenerative disc disease of the lumbar spine. Semin Spine Surg 19: 65-71.

Yoshikawa T, Ueda Y, Miyazaki K, Koizumi M, Takakura Y (2010) Disc regeneration therapy using marrow mesenchymal cell transplantation: a report of two case studies. Spine (Phila Pa 1976) 35: E475-480.

Zhang C, Berven SH, Fortin M, Weber MH (2016) Adjacent segment degeneration versus disease after lumbar spine fusion for degenerative pathology: a systematic review with meta-analysis of the literature. Clin Spine Surg 29: 21-29.

Zhou Z, Gao M, Wei F, Liang J, Deng W, Dai X, Zhou G, Zou X (2014) Shock absorbing function study on denucleated intervertebral disc with or without hydrogel injection through static and dynamic biomechanical tests in vitro. Biomed Res Int 2014: 461724.

Zobel BB, Vadala G, Del Vescovo R, Battisti S, Martina FM, Stellato L, Leoncini E, Borthakur A, Denaro V (2012) T1rho magnetic resonance imaging quantification of early lumbar intervertebral disc degeneration in healthy young adults. Spine (Phila Pa 1976) 37: 1224-1230.

\section{Discussion with Reviewers}

Zhen Li: What are the main advantages and disadvantages of using human IVD organ culture as compared with the other animal species? How is the reproducibility when using human IVDs obtained from patients?

Authors: There are several advantages in using human IVD culture for assessing tissue repair strategies. The most obvious advantage is that the main goal of the present study was to repair human IVDs and, therefore, assessing treatment within this tissue is very likely the most appropriate. Another advantage is that the cell density in the human IVD is as closely related as possible to patients seeking disc repair therapy, as opposed to bovine, ovine or porcine IVDs, which originate from young healthy animal and contain much higher cell density. For example, Liebscher et al. (2011, additional reference) show that cell density in human IVDs (aged 30-60, which fits the range for most of the study's donors) is approximately 1.8 million cells/g of tissue. For young, healthy bovine IVDs, the cell density is approximately 3.3 million cells/g of tissue (Boubriak et al., 2013, additional reference), which is almost the double. While the naturally-occurring degeneration of the isolated human IVDs may seem as a disadvantage, it is actually an advantage, as this is exactly the type of early degeneration that the present study aimed to treat with cell/gel therapy. Additionally, regardless of the degenerative state, use of T1@ MRI before treatment allowed to establish a baseline for normalisation following treatment, post-treatment MRI and histological evaluation. This also meant that T1@ MRI standardised the reproducibility using different human donors. There are also some disadvantages in using human IVDs. First, they are limited in supply and unpredictably available. They are quite heterogeneous (Mulligan et al., 2015, additional reference) and may not all respond in the same way to this type of autologous treatment. On the other hand, their heterogeneity also provides even more clinical relevance and may help in patient selection.

Laura Creemers: pNIPAM itself is non-degradable. To what extent is this material likely to be Food and Drug Administration (FDA)-approved for application inside the body? 
Authors: The pNIPAM used was, indeed, a nondegradable polymer. The non-degradability per $s e$ is not a limitation towards the FDA clearance of a non-permanent device for implantation. For example, poly ethylene oxide is not degradable, yet it is used in hydrogels, delivery systems and decoration of therapeutic proteins for improved pharmacokinetics (Ma et al., 2014, additional reference). Another non-degradable polymer with widespread use in hydrogels for parenteral administration is carboxymethyl cellulose (Varma et al., 2014, additional reference). Degradation is not the only clearance mechanism for polymers in the body. In fact, a polymer can undergo slow spontaneous dissolution or hydrolysis and fragments below around $25 \mathrm{kDa}$ can be eliminated through renal clearance (Woodard and Grunlan, 2018, additional reference).

As for the toxicity, the only concern is given by the presence of unreacted monomers, which should be thoroughly controlled during process validation. Again, other polymers used in patients are prepared from monomers very reactive and toxic [e.g. polyvinyl chloride (PVC), Teflon ${ }^{\mathrm{TM}}$ ] but safe when polymerised. Overall, while some studies are available (Cooperstein and Canavan, 2013; Cui et al., 2011; Vihola et al., 2005; additional references), further research is necessary to determine the biodistribution, elimination path, fate and safety of biomaterials containing pNIPAM for human use.

\section{Additional References}

Boubriak OA, Watson N, Sivan SS, Stubbens N, Urban JP (2013) Factors regulating viable cell density in the intervertebral disc: blood supply in relation to disc height. J Anat 222: 341-348.
Cooperstein MA, Canavan HE (2013) Assessment of cytotoxicity of ( $\mathrm{N}$-isopropyl acrylamide) and poly(N-isopropyl acrylamide)-coated surfaces. Biointerphases 8: 19.

Cui Z, Lee BH, Pauken C, Vernon BL (2011) Degradation, cytotoxicity, and biocompatibility of NIPAAm-based thermosensitive, injectable, and bioresorbable polymer hydrogels. J Biomed Mater Res A 98: 159-166.

Liebscher T, Haefeli M, Wuertz K, Nerlich AG, Boos N (2011) Age-related variation in cell density of human lumbar intervertebral disc. Spine (Phila Pa 1976) 36: 153-159.

Ma L, Deng L, Chen J (2014) Applications of poly(ethylene oxide) in controlled release tablet systems: a review. Drug Dev Ind Pharm 40: 845-851.

Mulligan KR, Ferland CE, Gawri R, Borthakur A, Haglund L, Ouellet JA (2015) Axial T1@ MRI as a diagnostic imaging modality to quantify proteoglycan concentration in degenerative disc disease. Eur Spine J 24: 2395-2401.

Varma DM, Gold GT, Taub PJ, Nicoll SB (2014) Injectable carboxymethylcellulose hydrogels for soft tissue filler applications. Acta Biomater 10: 4996-5004.

Vihola H, Laukkanen A, Valtola L, Tenhu H, Hirvonen J (2005) Cytotoxicity of thermosensitive polymers poly(N-isopropylacrylamide), poly(Nvinylcaprolactam) and amphiphilically modified poly(N-vinylcaprolactam). Biomaterials 26: 30553064.

Woodard LN, Grunlan MA (2018) Hydrolytic degradation and erosion of polyester biomaterials. ACS Macro Lett 7: 976-982.

Editor's note: The Scientific Editor responsible for this paper was Brian Johnstone. 